\title{
Heterogeneous Trade Costs and Wage Inequality: A Model of Two Globalizations *
}

\author{
Sergi Basco \\ $\mathrm{UC} 3 \mathrm{M}$
}

\author{
Martí Mestieri \\ TSE
}

First Draft: October 2008

This Version: September 2012

\begin{abstract}
We develop a model for analyzing the distributional effects of two globalizations and their interdependence. We distinguish between two trade cost reductions, (i) trade liberalizations in the 1980s, which increased trade in low-skill-intensive goods (denoted L-Globalization) and (ii) reductions in communication costs due to the IT revolution, which raised trade in middle-skill-intensive goods during the 1990s (denoted C-Globalization). We consider a North-South trade economy in which the North is skill abundant. A freely traded final good is produced using high-skill services and a bundle of inputs. Inputs differ on the intensity of middle- and low-skill workers required to be produced, and are subject to heterogeneous trade costs. In the North, we find that wage inequality increases in the L-globalization. During the C-globalization, wage polarization emerges. The relative wage of high- to middle-skill workers increases, while the relative wage of middle- to low-skill workers is hump-shaped. We find a complementarity between the two globalizations. Wage polarization is delayed by the extent of trade in the L-globalization. In the South, we find that wage inequality increases in both globalizations. Finally, we show how asymmetric participation in the C-globalization of two southern countries generates a discontinuous pattern of specialization. The southern country participating in the C-globalization specializes in the least and most skill-intensive traded inputs.
\end{abstract}

Keywords: globalization, wage inequality, wage polarization, pattern of specialization.

JEL Classification: F14, F16, F11.

\footnotetext{
${ }^{*}$ A previous version of this paper circulated under the title "A Model of Two Globalizations: implications for wage inequality and the pattern of specialization." We thank Daron Acemoglu, Pol Antràs and Arnaud Costinot for their guidance. We also thank James Anderson, David Autor, Abhijit Banerjee, Ricardo Caballero, Gene Grossman, Pablo Kurlat, Kiminori Matsuyama, Sahar Parsa, Mar Reguant, Esteban RossiHansberg, Robert Townsend, the editor, three anonymous referees and seminar participants at various institutions and conferences for useful comments and suggestions. David Autor and David Dorn generously shared their code and data with us. Basco acknowledges financial support from Fundación Ramón Areces, the Spanish Ministry of Science and Innovation (ECO2008-01300) and EFIGE (grant number 225551). Mestieri acknowledges financial support from Banco de España. We blame each other for all remaining errors. E-mail addresses: sergi.basco@uc3m.es and marti.mestieri@tse-fr.eu.
} 


\section{Introduction}

The skill content of North-South trade has changed over the last decades. Figure 1 documents the evolution of the share of southern exports in industries with skill intensity above the average skill intensity of U.S. industries. During the 1980s, southern exports increased relatively more in industries with skill intensity below the U.S. average. In the 1990s, this pattern reversed and southern exports grew disproportionally more in industries above the U.S. average skill intensity. ${ }^{1}$

These changes in southern exports can be exemplified by the bilateral trade of the United States with Chile and India. Figure 2 shows that in the 1980s, Chilean exports increased in below-average skill-intensive industries. During the 1990s, Indian exports rose in above-average skill-intensive industries. We interpret these differential increases in North-South trade as reductions in different trade costs. Chile underwent a dramatic trade liberalization in the late 1970s and 1980s, ${ }^{2}$ while India has benefited from offshoring of industries and services that make intensive use of information technologies (IT) in the 1990s. ${ }^{3}$ Our empirical analysis suggests that the trade patterns described for India and Chile hold more broadly.

Based on this evidence, we distinguish between two globalization processes. First, we denote by L-globalization the trade Liberalizations occurred during the late 1970s and 1980s that increased northern imports in low-skill-intensive industries. Second, we denote by $C$ globalization the reduction in Communication costs driven by the IT revolution, which increased northern imports in middle-skill-intensive industries during the 1990s. In our model, these differences in trade composition arise as a result of differential reductions in trade costs across skills. Thus, the key feature of our model is to analyze trade cost reductions that are heterogeneous across skills and over time.

We analyze these two globalizations and their complementarity. We investigate the effects of the IT-driven trade (C-globalization) on wage inequality and the pattern of specialization, and how these effects depend on the extent of trade done during the L-globalization.

We find that the relative wage of high- to middle-skill workers in the North increases with the C-globalization. On the contrary, the relative wage of middle- to low-skill workers is hump-shaped as IT-driven trade progresses. This is because the relative wage of northern middle- to low-skill workers starts to decline when above-average skill jobs are offshored,

\footnotetext{
${ }^{1}$ A similar U-shape pattern emerges when looking at the median skill rather than the average, or when restricting the sample to the U.S. or G-7 countries. A southern country is defined as having less than half of 2000 U.S. GDP per capita PPP adjusted. Skill intensity is constructed from U.S. census data, based on educational attainment of workers in different jobs. The average skill intensity of U.S. imports is the average of the skill intensity of each industry at 3-NAICS level. We use data on trade flows from the Feenstra database, note that data pre- and post-1984 data come from different sources (Feenstra et al., 2005).

${ }^{2}$ This pattern is not specific for Chile. Goldberg and Pavcnik (2007) document that trade liberalizations in the 1970s and 1980s were biased towards low skill-intensive industries. Amongst others, they cite Hanson and Harrison (1999) and Robertson (2000, 2004) for Mexico, Currie and Harrison (1997) for Morocco and Attanasio et al. (2004) for Colombia.

${ }^{3}$ India is one of the countries which has benefited the most from this new wave of offshoring. Trefler (2006) documents that India hosted the highest number of new IT services projects (around $19 \%$ of the world total) and call centers (around 12\% of the world total) in 2003 and 2004.
} 
which happens during the C-globalization. This decline in the relative wage of middle- to low-skill workers together with the increase in the relative wage of high-skill workers has been termed "wage polarization." 4 Thus, the equilibrium wage distribution tends to wage polarization as the C-globalization process progresses.

Our first main result shows that there exists a complementarity between the two globalizations. We find that wage polarization is delayed by the extent of trade done during the L-globalization. The intuition for this result is that trade in low-skill-intensive inputs increases the average skill requirement of northern industries, which delays wage polarization. This complementarity result highlights the importance of having a unified view of the two phases of globalization, which is one of the novelties of our framework. We provide empirical evidence supporting the complementarity result. We show that countries that have traded more during the L-globalization experience smaller drops in lower-tail wage inequality during the 1990s.

We extend our baseline model to allow for two southern countries, with only one participating in the C-globalization. We want to capture the idea that there is asymmetric participation within southern countries because some countries may lack the minimum stock of specific capital needed to benefit from the IT revolution. Our second main result shows that asymmetric participation among southern countries generates a discontinuous pattern of specialization. The southern country participating in C-globalization specializes in the least skill-intensive L-globalization goods, in addition to C-globalization goods. The other southern country specializes in the relatively higher skill-intensive goods of the Lglobalization. Wage inequality increases in the former and decreases in the latter. Using data on Internet adoption, we provide evidence consistent with an asymmetric pattern of specialization amongst southern countries.

Section 2 provides suggestive evidence supporting our modeling assumptions. We present evidence consistent with trade liberalizations affecting low-skill-intensive industries in the L-globalization, and a fall in communication costs mainly affecting middle-skillintensive industries in the C-globalization. For the L-globalization, we show that U.S. tariff reductions were biased towards low-skill-intensive industries during the 1980s. For the C-globalization, we show that high levels of Routine Task Intensity (RTI) are associated with middle-skill-intensive industries. We interpret the RTI index as a proxy for offshorability in the presence of a reduction in communication costs (IT revolution). ${ }^{5} \mathrm{We}$ also show that countries with lower communication costs export to the U.S. relatively more in skill-intensive industries. Finally, we relate changes in U.S. trade openness and changes

\footnotetext{
${ }^{4}$ See Autor et al. (2008), Goos and Manning (2007) and the references therein.

${ }^{5}$ Oldenski (2011) shows that the most routine tasks are the most likely to be offshored. The RTI measure is closely related to impersonal services, which Blinder (2006) emphasizes as a distinctive element of C-globalization trade. The use of the RTI is motivated by the observation that goods that can be electronically delivered (or monitored) are fairly standardized and follow determined procedures. The Index is taken from Autor and Dorn (2009), who also link the IT revolution with the loss of middle-skill-intensive jobs in northern industries. In this paper, we focus on the role of offshoring of jobs to the South rather than the substitution of jobs by computers emphasized by Autor and Dorn.
} 
in wages across different levels of skill. We find that openness is negatively correlated with the U.S. wage bill in low-skill-intensive industries in the 1980s. During the 1990s, we find that this correlation is negative for middle-skill-intensive industries.

Our model, presented in Section 3, features a North-South trade economy. A freely traded final good is produced in the North by combining a bundle of inputs and highskill labor. This bundle is assembled using a continuum of inputs, which are produced by middle- and low-skill labor in different proportions. Thus, this model can be thought of as an offshoring decision by northern firms. We assume that the North is skill-abundant and that there are heterogeneous trade costs across different inputs.

We model the two globalizations as changes in the trade costs of different inputs. There exists a continuum of inputs $z \in[0,1]$ where $z$ captures how middle-skill-intensive each input is. The L-globalization is modeled as a reduction in trade costs associated with lowskill-intensive inputs, that is, with inputs with skill intensity $0<z<\bar{z}$, where $\bar{z}$ is some exogenous value. We label these inputs as intermediates. The second phase is modeled as a decrease in trade costs associated with middle-skill-intensive inputs, $z>\bar{z}$, which we denote as tasks. During both phases, we assume that marginal decreases in trade costs happen for inputs that are relatively more skill intensive. This implies that the skill content of trade is increasing in both globalizations, which is consistent with Figures 3a and 3b. They show that the skill content of trade flows below (above) the average skill content increases during the $\mathrm{L}(\mathrm{C})$-globalization.

Section 4 presents the main results. In the L-globalization, the set of low-skill-intensive intermediates imported from the South increases. As in Wood (1995) and Feenstra and Hanson (1996), since the skill requirement of the intermediates imported by the North is below its mean skill intensity, the relative demand for middle-skill workers increases, thereby raising their relative wage. Moreover, the wage of high-skill workers relative to both middle- and low-skill agents increases because more intermediates can be bought at cheaper prices and demand for northern intermediates decreases. In the C-globalization, the set of traded tasks increases. The relative wage of high-skill workers increases for the same reasons as in the L-globalization. The relative wage of middle- to low-skill workers exhibits a hump-shaped pattern. The reason is that the relative demand of northern middle-skill workers declines only when the marginal task being offshored to the South is above the skill intensity of the average input produced in the North after the first phase of globalization. Thus, the equilibrium tends to wage polarization in the North.

We find a complementarity between trade in the two globalizations. Wage polarization is delayed by the extent of trade in the L-globalization. A larger set of traded low-skillintensive intermediates implies a higher skill intensity of the average input produced in the North. Thus, more trade in intermediates allows a larger set of tasks to be offshored during the $\mathrm{C}$-globalization before the relative wage of northern middle-skill workers starts to decline. We provide empirical evidence consistent with this prediction. We find a positive relationship between trade openness before the onset of the IT revolution and changes in lower-tail northern wage inequality in the 1990s. 
In the South, relative wages increase in the two globalizations. The intuition is analogous to Wood (1995) and Feenstra and Hanson (1996): the marginal input being offshored is relatively more skill-intensive, which raises the relative demand of middle-skill labor and the relative wage throughout the globalization process.

Subsection 4.2 introduces a second southern country to study how asymmetric participation in the IT-driven trade affects the pattern of specialization and wage inequality in the South.We assume that only one southern country can participate in the C-globalization. In equilibrium, this country exports tasks to the North and the relative wage of low-skill workers in this country decreases. Thus, this country gains comparative advantage in the least skill-intensive intermediates, which generates a discontinuous pattern of specialization. The most and least skill-intensive traded inputs are produced by this southern country. As the second phase of globalization progresses, the equilibrium tends to complete specialization. One South produces tasks and the other, intermediates. The relative wage of middle-skill workers increases in the South participating in the C-globalization, while it declines in the other. We provide evidence for the changes in the pattern of specialization amongst southern countries consistent with the predictions of our model. We show that southern countries with a high stock of IT technologies tend to increase exports in industries with levels of RTI above average (which are middle-skill-intensive), and decrease exports in industries with skill intensity below-average.

Section 5 relaxes the assumption on the exogenous supply of labor. Since we are considering labor demand shocks during a long period of time, we allow for endogenous supply decisions. We show that the comparative statics for wages derived in the baseline model hold in this extended version. Moreover, we find that the mass of northern agents selecting into middle-skill jobs increases during the L-globalization and eventually shrinks during the C-globalization. This is consistent with the empirical evidence on job polarization in the North, see for example Autor et al. (2008). Section 6 concludes.

\section{Motivating Evidence and Related Literature}

In this section we present evidence that points towards two phases of globalization characterized by changes in trade costs affecting industries of different skill-intensity. Motivated by this evidence, our paper focuses on the effects of heterogeneous changes in trade costs on wage inequality and the pattern of specialization. To the best of our knowledge, our work is the first attempt to provide a unified view of the globalization process and its effect on wage inequality, both across North-South trade and between different southern countries.

\subsection{Motivating Evidence}

The premise of our analysis is that trade costs have changed differentially across sectors of different skill intensity over time. The overall evidence in this section paints a picture of two different phases of globalization: an L-globalization, driven by trade liberalizations which increased trade in low-skill-intensive industries and affected the relative demand of low- 
skill workers; and a C-globalization characterized by a fall in communication costs, which raised trade in intermediate skill-intensive industries and affected the relative demand of middle-skill workers. Finally, we show that the skill content of southern exports increased in below-average skill-intensive industries during the L-globalization and in above-average skill-intensive industries during the C-globalization.

We present our findings in three steps. First, we document heterogeneous changes in trade costs across skill and over time. Second, we relate these changes to trade flows and the relative demand of skill. Third, we report the evolution of the skill content of southern exports in industries with skill requirement below and above the U.S. average.

The first piece of evidence on heterogeneous changes in trade costs comes from analyzing changes in U.S. tariffs and transportation costs over time. Our data is disaggregated at 3-digit NAICS and we use educational attainment of workers in an industry from the U.S. census as proxy for industry skill intensity. First, we find that tariff reductions between 1978 and 1988 were concentrated in low-skill industries (Figure 4a). This result is similar to Haskel and Slaughter (2003), who use non-production workers to proxy for skill. Second, we show that changes in U.S. tariffs were not significantly different from zero at any level of skill intensity during the 1990s (Figure 4b). Third, we show that changes in transportation costs were not statistically different from zero at any level of skill, neither in the 1980s, nor in the 1990s (Figure 5). This evidence is consistent with Hummels (2007) findings for the ad-valorem shipping cost not having changed much since the 1950s. There is a growing literature emphasizing that there are more dimensions in trade costs than tariffs and transportation costs, e.g., Hummels (2007). However, data along other dimensions of trade costs are difficult to obtain, specially for non-tariff barriers (Anderson and van Wincoop, 2004) and we abstract from them.

Our second piece of evidence on heterogeneous changes in trade costs aims at capturing some of the effects of the IT revolution. During the 1990s, new jobs such as telephone operators or data entry keyers started to be offshored (Trefler, 2006). The standard measures of trade costs are less relevant for this new trade pattern. A common characteristic of these new tasks being offshored is that they are standardized and follow tight and determined procedures. In order to capture this feature, we use the Routine Task Intensity (RTI) index from Autor and Dorn (2009) as a proxy for "offshorability." The argument is that a reduction in communication costs (IT revolution) makes jobs with high RTI index more likely to be offshored. ${ }^{6}$ Oldenski (2011) and Crinò (2010) provide empirical evidence consistent with this argument, showing that routine tasks are more likely to be offshored. ${ }^{7}$ Figure 6 reports anecdotal evidence pointing that higher RTI jobs are performed by middle-skill workers. It suggests that there exists an inverse U-shape relationship between skill intensity and RTI,

\footnotetext{
${ }^{6}$ Each job is assigned a routine and a manual score, and this index is the log ratio of the two. Therefore, tasks with high RTI imply a high routine and a low manual score. The RTI index assigns a value of "routine intensity" to a representative set of 332 occupations in the U.S. census. See Autor and Dorn (2009) for further details. Note that the findings reported in Blinder and Krueger (2009) are not inconsistent with the use of the RTI index as proxy for offshorability. The reason is that Blinder and Krueger only consider a measure of routine that abstracts from the manual content of a job.

${ }^{7}$ Grossman and Rossi-Hansberg (2006), Ebenstein et al. (2011) also relate routine indices with offshoring.
} 
which we find when aggregating at the industry level (Figure 7). ${ }^{8}$

Next, we investigate how trade flows relate to changes in the trade costs described above. More specifically, we analyze the relationship between U.S. imports and tariffs and communication costs for different levels of industry skill-intensity. We use Internet adoption at country level as a proxy for communication costs. The reason is that goods that become offshorable can be electronically delivered (e.g., data entry keyers) or require intense usage of IT (e.g., call centers). We run the following regression for 1990 and 2000,

$$
X_{i c}=\alpha+\beta \tau_{i}+\gamma \text { Internet }_{c} \cdot \text { Skill Intensity }_{j}+\delta_{j}+\delta_{c}+\varepsilon_{i c}
$$

where $X_{i c}$ are exports of product $i$ from country $c$ to the United States, $\tau_{i}$ is U.S. tariff on product $i$, Internet ${ }_{c}$ is the fraction of the population with access to Internet in country $c$, Skill Intensity ${ }_{j}$ is the average skill of industry $j$ and $\delta_{j}$ and $\delta_{c}$ represent industry and country fixed effects, respectively. ${ }^{9}$

Column 1 of panel A in Table 1 shows a negative, significant correlation between tariffs and U.S. imports in 1990. This correlation is larger when the sample is restricted to southern countries (column 4). Panel B reports not significant coefficients on tariffs for year 2000. In contrast, the coefficient on the interaction between Internet and Skill Intensity is positive and significant when restricting the sample to the South (column 5), pointing at a differential effect of the IT revolution on poor countries. ${ }^{10}$ Note that our results abstract from trade in services, because these data are not available. We think this lack of data on services underestimates our results because offshored services are RTI intensive and, as argued by Markusen (2006) and Markusen and Strand (2008), require above-average skills to be produced.

We investigate how the relative demand for skill relates to trade flows over time. We report how changes in the wage bill paid by different U.S. industries are correlated with changes in U.S. trade. Column 1 in Table 2 reports the results of regressing the change in U.S. wage bill during the 1980s on the interaction of average industry skill with the change in trade openness. ${ }^{11}$ The coefficient is positive and significant. Column 2 shows

\footnotetext{
${ }^{8}$ The maximum in RTI intensity corresponds to industries with an average worker reporting "Some College, No degree" educational level.

${ }^{9}$ U.S. imports are from Feenstra's data base and U.S. tariffs come from Romalis. Romalis' tariff data starts in 1989, thus we can only test for the last years of our Fist Globalization. Our measure of industry is a 3-digit NAICS and of product is a 6-digit HS. There are no data for Internet adoption in 1990 (presumably it was negligible for most of the sample).

${ }^{10}$ In this sample the highest skill intensity level is 11.4 , which roughly coincides with skill level associated with the largest RTI. As robustness checks we added additional controls. One could think that our Internet adoption measure could be a proxy for other country variables such as country wealth, human capital levels and financial development and therefore their interaction with skill intensity could be relevant. Our coefficients of interest remained significant and with similar values to the baseline regression when adding these additional covariates. A second robustness check is to control for the potential endogeneity of our measure of skill intensity. In order to address this concern, we instrument skill intensity with the RTI index. Our exclusion restriction is that RTI only affects exports through the level of skill intensity of an industry. Columns 3 and 6 report the previous regressions using this instrumental variable approach. The coefficients of interest remain significant and with the expected sign.

${ }^{11}$ We use the U.S. wage bill data for 1980-1996 constructed in Autor et al. (1998). Our trade openness measure is the share of exports plus imports over GDP from the Penn World Tables.
} 
that the coefficient on the interaction term is not significant for the 1990s. Yet, when we add a quadratic term, the coefficients become significant, as shown in column 3. These regression coefficients imply a U-shape pattern for the response of wage bill to increases in trade. These results suggest that the relationship between trade and demand for skill has changed over time.

Finally, Figure 3a and 3b report the skill content of southern exports in industries with skill requirement below and above the U.S. average, respectively. These figures point to an increase in the skill content of southern exports in below-average skill-intensity during the L-globalization and above-average skill-intensity in the C-globalization. This suggestive evidence will motivate our comparative statics exercises in Section $4 .^{12}$

\section{$2.2 \quad$ Related Literature}

This paper relates to a rich and diverse literature on international trade, wage inequality and the patterns of specialization. Our L-globalization comparative statics results are related to standard Heckscher-Ohlin models and the work of Wood (1995) and Feenstra and Hanson (1996). Feenstra and Hanson provide a rationale for increasing inequality in both the North and the South. They analyze the effect of capital inflows to the South in the context of a free trade equilibrium. These capital inflows reduce the unit cost of production in the South, allowing the South to produce more (relatively) skill-intensive goods at the margin. The mechanics of our comparative statics for the L-globalization is similar. However, their comparative statics exercise is different from ours, as we focus on changes in trade costs. Another important difference is that our framework, by assuming heterogeneous trade costs, allows us to study the two waves of globalization and their interdependence.

Our analysis of the C-globalization bears upon the literature on offshoring, outsourcing and wage inequality. It includes, among others, Antràs et al. (2006a,b), Dinopoulos et al. (2009), Grossman and Rossi-Hansberg (2008), Markusen and Strand (2008) and Zhu and Trefler (2005). Our paper shares the emphasis on middle-skill agents as in Antràs et al. (2006b). They focus on team problem solving. In contrast, we consider a segmented production process with firms supplying inputs, which enables us to distinguish the effects of different changes in trade costs on wage inequality. Grossman and Rossi-Hansberg (2008) consider the effect of heterogeneous transportation costs. However, they assume that tasks can be so perfectly partitioned that a fall in trade costs only affects one type of labor.

Anderson (2009), Costinot and Vogel (2010), Grossman and Maggi (2000) and Ohnsorge and Trefler (2007) among others study the role of sorting for wage inequality and the pattern of specialization. They emphasize the difference between North-South and North-North trade, from which we abstract. However, they ignore the differential effect of heterogeneous changes in trade costs across sectors of different skill-intensity.

\footnotetext{
${ }^{12}$ To perform this exercise we hold the skill requirement of an industry fixed at the level of the United States. Then we compute the weighted average of the skill embodied in southern exports. Both figures use non-production workers data from BLS. These findings are robust to consider only U.S. or G-7 imports. We find similar qualitative results when we use the skill-intensity index constructed from U.S. census data.
} 
Finally, a new series of recent papers document heterogeneous effects of offshoring on wage inequality by skills, which are consistent with the assumptions and predictions of our model. Ebenstein et al. (2011) document sizable within-occupation changes in U.S. wages related to North-South trade. They show that workers experiencing higher wage declines are those in RTI-intensive occupations and those without higher education (and old workers). These negative effects are only significant in the later periods of their sample, 1992-2002, and not during the 1980s. Hummels et al. (2011), by analyzing Danish data from 1995-2006, show that offshoring tends to increase the wage of those with tertiary education and decrease it for the others. Moreover, they find that workers whose occupations involve routine tasks suffer larger wage falls. On a similar vein, Oldenski (2012) finds that U.S. multinationals tend to offshore routine-intensive jobs. Other papers report heterogeneous effects of offshoring across skill levels and routinization. These include Crinò (2010), Autor et al. (2011) and Liu and Trefler (2011). ${ }^{13}$

\section{Model}

In this section we present a simple model to study the effects of the two phases of globalization. A freely traded final good is produced in the North using high-skill labor and a bundle of inputs, which are produced by middle- and low-skill workers. Inputs are subject to heterogeneous trade costs, which enable us to frame our two globalizations in a tractable manner. Section 4 derives the main results of the paper performing comparative statics on trade costs. The baseline model abstracts from endogenous labor supply decisions. Section 5 shows that the results derived for the baseline case hold when there is a continuum of types and each type endogenously selects into one occupation.

\subsection{Baseline Model}

We consider a competitive world economy consisting of two countries, the North, $N$, and the South, $S$. Each country is populated by a mass one of agents, which cannot migrate. Each agent is endowed with one unit of labor that inelastically supplies to the market. Northern agents can be divided between low-, middle- and high-skill types. The fraction of each type is $1-\theta^{N}, \theta^{N}(1-\varphi)$ and $\theta^{N} \varphi$, respectively. Our interpretation is that a fraction $\theta^{N}$ has basic education and a fraction $\varphi$ obtains further education. We assume that $\varphi=0$ in the South. Thus, southern population can be divided between a fraction $1-\theta^{S}$ of low and a fraction $\theta^{S}$ of middle-skill agents. Finally, we assume that the South is relatively abundant in low-skill labor, i.e., $\left(1-\theta^{S}\right) / \theta^{S}>\left(1-\theta^{N}\right) / \theta^{N}(1-\varphi)$.

All agents have the same utility function, $u(c)$, where $c$ is final good consumption. The

\footnotetext{
${ }^{13}$ Labor economists have documented large changes in wage inequality (mostly for the U.S.), which our findings relate to. This vast literature includes Katz and Murphy (1992), Acemoglu (1999), Autor et al. (2003), Autor et al. (2008), Goos and Manning (2007) and Autor and Dorn (2009) among others.
} 
final good is produced by combining a bundle of inputs $B$ and high-skill services $h$,

$$
Y=h^{\alpha} B^{1-\alpha}, \quad \alpha \in(0,1)
$$

$h$ can be thought of as headquarter services, which are provided by high-skill agents. The bundle is made by assembling a continuum of inputs, $I(z)$, with $z \in[0,1],{ }^{14}$

$$
B=\exp \left[\int_{0}^{1} \ln I(z) d z\right]
$$

Each input is produced using a Cobb-Douglas production function

$$
I(z)=\left(\frac{m(z)}{z}\right)^{z}\left(\frac{l(z)}{1-z}\right)^{1-z} \text { for each } z \in[0,1]
$$

where $m(z)$ and $l(z)$ denote middle- and low-skill workers employed in the production of input $z$, respectively. Note that $z$ parametrizes the skill-intensity required to produce each input. The higher $z$ is, the more middle-skill-intensive the input is.

The final good is assumed to be freely traded and we normalize its price to one throughout the paper. Inputs are subject to heterogeneous iceberg costs. For one unit of input $z$ to arrive at home, $\tau(z) \geq 1$ units must be purchased abroad. ${ }^{15}$

\subsection{Trade Equilibrium}

The problem of the final good producer is

$$
\max _{\left\{h, I^{i}(z)\right\}_{z \in[0,1]}} h^{\alpha}\left(\exp \left[\int_{0}^{1} \ln I^{i}(z) d z\right]\right)^{1-\alpha}-w_{h} h-\int_{0}^{1} p^{i}(z) I^{i}(z) d z
$$

which implies that the demand for high-skill services and each input $z$ are

$$
\begin{aligned}
\alpha Y & =w_{h} h, \\
(1-\alpha) Y & =p^{i}(z) I^{i}(z) .
\end{aligned}
$$

Consider the problem of an input producer in country $i$,

$$
\max _{\left\{m^{i}(z), h^{i}(z)\right\}_{z \in[0,1]}} p^{i}(z)\left(\frac{m^{i}(z)}{z}\right)^{z}\left(\frac{l^{i}(z)}{1-z}\right)^{1-z}-w_{m}^{i} m^{i}(z)-w_{l}^{i} l^{i}(z) .
$$

\footnotetext{
${ }^{14}$ The aggregation of inputs in a bundle is similar to the production function in Dixit and Grossman (1982).

${ }^{15}$ The assumption that the final good is traded at no cost is not crucial for our results. Our comparative statics results rely on heterogeneous changes in trade costs of middle- and low-skill industries. Changes in trade cost of the final good do not affect relative demand of middle- and low-skill workers because of the homotheticity of the final good production function. In the on-line Appendix we analyze two similar models with three types in both North and South and derive qualitatively analogous results. In these versions, both North and South high-skill workers produce final good.
} 
The labor demands of a producer of input $z$ in country $i$ are given by

$$
\begin{aligned}
z p^{i}(z) I^{i}(z) & =w_{m}^{i} m^{i}(z), \\
(1-z) p^{i}(z) I^{i}(z) & =w_{l}^{i} l^{i}(z) .
\end{aligned}
$$

The labor market clearing conditions are obtained by integrating labor demands across all input producers in each country

$$
\begin{aligned}
w_{h} & =\alpha \frac{Y}{\theta^{N} \varphi} \\
\int_{0}^{1} m^{N}(z) d z & =(1-\alpha) Y \int_{0}^{1}\left(\mathbb{1}_{d}^{N}(z)+\frac{\mathbb{1}_{x}^{N}(z)}{\tau(z)}\right) \frac{z}{w_{m}^{N}} d z=\theta^{N}(1-\varphi), \\
\int_{0}^{1} l^{N}(z) d z & =(1-\alpha) Y \int_{0}^{1}\left(\mathbb{1}_{d}^{N}(z)+\frac{\mathbb{1}_{x}^{N}(z)}{\tau(z)}\right) \frac{(1-z)}{w_{l}^{N}} d z=1-\theta^{N}, \\
\int_{0}^{1} m^{S}(z) d z & =(1-\alpha) Y \int_{0}^{1} \frac{\mathbb{1}_{x}^{S}(z)}{\tau(z)} \frac{z}{w_{m}^{S}} d z=\theta^{S}, \\
\int_{0}^{1} l^{S}(z) d z & =(1-\alpha) Y \int_{0}^{1} \frac{\mathbb{1}_{x}^{S}(z)}{\tau(z)} \frac{(1-z)}{w_{l}^{S}} d z=1-\theta^{S}
\end{aligned}
$$

where $\mathbb{1}_{d}^{i}(z)$ and $\mathbb{1}_{x}^{i}(z)$ are indicator functions for each input $z$ being produced in country $i$ for domestic consumption and for exporting, respectively.

Definition A competitive equilibrium for a given trade cost structure $\tau(z)$ is a set of prices $p^{i}(z)$ for each input $z$ and country $i \in\{N, S\}$, a price for the final good $p_{f}(\equiv 1)$, a wage for low-skill workers $w_{l}^{i}$, a wage for middle-skill workers $w_{m}^{i}$, a wage for northern highskill workers $w_{h}^{N}$, an allocation of low-skill $l^{i}(z)$ and middle-skill $m^{i}(z)$ labor across inputs producers and a consumption choice $c^{i}$ for each agent in country $i$ such that: relative wages follow from factor demands and market clearing conditions, equations (10) to (14), $p^{i}(z)$ follows from the demand function (7), the allocations of middle- and low-skill labor, $m^{i}(z)$ and $l^{i}(z)$, is consistent with profit maximization, (8) and (9), and consumption is equal to income.

\section{Main Results}

In this section we present the two main results of the paper. Subsection 4.1 derives the distributional consequences of the L- and the C-globalizations and shows the complementarity between the two. Subsection 4.2 extends the baseline model by dividing the original South in two different southern countries which open differently to trade in the C-globalization. Our second main result establishes how the patterns of specialization and wage inequality depend on the differential participation in the C-globalization. 


\subsection{The Two Globalizations and their Complementarity}

This section performs comparative statics for the two globalizations on relative wages. Then, we present our first main result (complementarity), which shows that trade in the L-globalization delays the emergence of wage polarization in the North during the C-globalization.

\subsubsection{The L-globalization}

Section 2 characterized the L-globalization as a decrease in trade costs of the least skillintensive inputs. To study its effects in a parsimonious way, we assume that trade is only possible in inputs with an index lower than $z_{I}$. In other words, trade costs are

$$
\tau(z)= \begin{cases}1 & \text { for } z \leq z_{I} \\ \infty & \text { otherwise }\end{cases}
$$

We formally define L-globalization as an increase in the set of traded intermediates, $z_{I}{ }^{16}$ This implies that the skill requirement of the marginal traded intermediate increases with globalization, which is consistent with the fact documented in Figure 3a. ${ }^{17}$ Therefore, the comparative statics exercise we are interested in is an increase in $z_{I}$.

Assumption $1 z_{I}<z^{*}\left(\theta_{N}, \theta_{S}\right)<1$, where $z^{*}\left(\theta_{N}, \theta_{S}\right)$ is implicitly defined as

$$
\left(\frac{1-z^{*^{2}}}{z^{*^{2}}} \frac{\theta_{S}}{\theta_{N}}\right)^{z^{*}}\left(\frac{\left(1-z^{*}\right)^{2}}{1-\left(1-z^{*}\right)^{2}} \frac{1-\theta_{S}}{1-\theta_{N}}\right)^{1-z^{*}}=1
$$

This assumption implies that all traded inputs are produced in the South. It can be interpreted in economic terms as follows. Given that the cost of input production is a combination (geometric mean) of the wage of low- and middle-skill workers, we require that the relative endowments are such that the comparative advantage of the South in using low-skill workers is stronger than the comparative advantage of the North in middleskill workers, so that all traded inputs are cheaper in the South. The North exports the final good to ensure trade balance.

Proposition 1 (L-globalization) The L-globalization features an increase of the relative wage of middle- to low-skill workers in both North and South. The relative wage of northern high-skill workers increases.

\footnotetext{
${ }^{16}$ The threshold $z_{I}$ can be endogenized as an equilibrium outcome in a model with constant iceberg costs $\tau(z)=\tau$ on intermediates. The reason is that the South has comparative advantage in low-skill-intensive inputs. In this case, our L-globalization comparative statics exercise (i.e., an increase in $z_{I}$ ) could be endogenously obtained as a decrease in $\tau$.

${ }^{17}$ Our qualitative results would hold if we allowed for $\tau(z)=1$ for $z \in\left[\underline{z}, z_{I}\right]$, with $\underline{z}>0$. The key assumption is that an increase in the set of traded inputs in the L-Globalization translates into an increase in the relative demand of middle-skill labor in the South.
} 
The proof follows from using equations (10) to (14) and the trade cost structure (15). The relative wages of northern high-skill workers are

$$
\frac{w_{h}^{N}}{w_{m}^{N}}=\frac{\alpha}{1-\alpha} \frac{1-\varphi}{\varphi} \frac{2}{1-z_{I}^{2}}, \quad \frac{w_{h}^{N}}{w_{l}^{N}}=\frac{\alpha}{1-\alpha} \frac{1-\theta^{N}}{\theta^{N} \varphi} \frac{2}{\left(1-z_{I}\right)^{2}},
$$

They are increasing in $z_{I}$ because more intermediates can be bought at cheaper prices for final good production and demand for northern intermediates decreases. The relative wages of middle- to low-skill workers are

$$
\frac{w_{m}^{N}}{w_{l}^{N}}=\frac{1-\theta^{N}}{\theta^{N} \varphi} \frac{1+z_{I}}{1-z_{I}}, \quad \frac{w_{m}^{S}}{w_{l}^{S}}=\frac{1-\theta^{S}}{\theta^{S}} \frac{z_{I}^{2}}{1-\left(1-z_{I}\right)^{2}} .
$$

By inspection, the relative wages are increasing in $z_{I}$. Note that the relative wages consist of two parts. The first term, containing $\theta^{i}$, corresponds to the relative supply (of lowskill agents), while the second term, containing $z_{I}$, corresponds to the relative demand. Therefore, our L-globalization comparative statics represents a shift in the relative demand curves, while keeping the relative supply fixed.

The relative wage of middle- to low-skill workers in the North increases because it offshores the least skill-intensive inputs. As a result, the relative demand of middle-skill workers increases, thereby increasing the relative wage. ${ }^{18}$ The relative wage of middleto low-skill workers also increases in the South. The reason is that an increase in traded intermediates (i.e., an increase in $z_{I}$ ) translates into a larger relative demand of middle-skill jobs. This result is similar to Wood (1995) or Feenstra and Hanson (1996). ${ }^{19}$

\subsubsection{The C-globalization and the Complementarity Result}

Based on our results in Section 2, we characterize the C-globalization as an increase in traded middle-skill-intensive inputs. We argued that the reduction in communication costs was the driver of the C-globalization and it mainly affected trade in middle-skill-intensive industries. Thus, we add to the set of traded intermediates a new set of tradeable tasks. Given that the nature of the trade costs driving the two globalizations is different, it is natural to allow for the two sets to be possibly disjoint. We frame this observation in the following trade cost structure

$$
\tau(z)= \begin{cases}1 & \text { for } z \leq z_{I} \text { and } \bar{z} \leq z \leq z_{I I} \\ \infty & \text { otherwise }\end{cases}
$$

where $0 \leq z_{I} \leq \bar{z} \leq z_{I I}<1$. This means that, in addition to the L-globalization trade in intermediates $z \in\left[0, z_{I}\right]$, we now allow for trade in more skill-intensive tasks $z \in\left[\bar{z}, z_{I I}\right]$.

\footnotetext{
${ }^{18}$ In fact, we find that real wages of northern low- and middle-skill workers fall during the L-globalization. This is consistent with the U.S. wage data, e.g., Katz and Murphy (1992). As pointed out by Acemoglu and Autor (2012), the canonical model of skill-biased technological change cannot deliver this prediction.

${ }^{19}$ There is mixed evidence on the effects of trade on inequality in the South, e.g., Goldberg and Pavcnik (2007).
} 
We formally define the C-globalization as an increase in $z_{I I}$, which is consistent with the evidence presented in Figure 3b. Thus, the comparative statics exercise that we perform is to increase the set of traded inputs with skill intensity above $\bar{z}$ by increasing $z_{I I}$.

Allowing for the sets of traded inputs in the two globalizations to be disjoint enables us to have a natural measure of depth of the L-globalization. Other formulations that do not rely on disjoint sets are possible and deliver similar insights. The two key assumptions are (i) trade during the C-globalization affects more skill-intensive industries than during the L-globalization and (ii) the set of inputs that can be traded increases by incorporating inputs that are relatively more skill-intensive. These two assumptions are borne out by the data, as discussed above.

Assumption $2 z_{I I}<z^{*}\left(\theta_{N}, \theta_{S}\right)$, where $z^{*}\left(\theta_{N}, \theta_{S}\right)$ is implicitly defined in equation (16).

Assumption 2 ensures that in equilibrium the South produces all traded inputs.

Proposition 2 (C-globalization) During the $C$-globalization, the relative wage of middleto low-skill workers in the North has an inverse U-shape pattern. It increases in $z_{I I}$ for $z_{I I}<\tilde{z}_{I I}\left(z_{I}, \bar{z}\right)$ and decreases thereafter. The relative wage of high-skill workers in the North and the relative wage of middle- to low-skill workers in the South increase in $z_{I I}{ }^{20}$

The intuition for the comparative statics of the relative wage of middle-skill workers in the North is as follows. Suppose that $\bar{z}=1 / 2$. To a first order approximation (for small $\left.z_{I}\right)$, the threshold $\tilde{z}_{I I}\left(z_{I}, \bar{z}=1 / 2\right)$ is the arithmetic mean of the skill intensity of inputs produced in the North after the L-globalization, i.e., $\tilde{z}_{I I}\left(z_{I}\right)=\frac{1+z_{I}}{2}$. Therefore, when the North offshores tasks with a skill requirement below the skill intensity of the average input produced domestically, the relative demand of middle-skill workers increases, raising the relative wage. Conversely, the relative wage decreases when the tasks being offshored require a skill intensity higher than the skill requirement of the average input. The relative wage of high-skill workers increases because the bundle of imported inputs increases, while demand for northern middle- and low-skill workers declines. These results imply that the equilibrium tends to wage polarization: the relative wage of high- to middle-skill workers increases and the relative wage of middle- to low-skill workers eventually decreases. The relative wage in the South increases in the C-globalization. The reason is that the marginal input being offshored is more skill-intensive, which raises the relative demand of middle-skill workers.

Our results for the evolution of the wage distribution in the North are consistent with the $90 / 50$ and 50/10 measures of U.S. wage inequality in the last three decades, documented in Autor et al. (2008). Namely, the 90/50 measure has steadily increased, and the 50/10 increased during the 1980s, flattening and, eventually declining thereafter.

Proposition 3 (Complementarity in the North) The threshold $\tilde{z}_{I I}\left(z_{I}, \bar{z}\right)$ is increasing in $z_{I}$.

${ }^{20}$ All remaining proofs can be found in Appendix A. 
Proposition 3 shows that the threshold below which the relative wage of northern middleto low-skill workers rises, $\tilde{z}_{I I}$, increases with the extent of L-globalization, $z_{I I}$. Figure 8 provides a graphical representation of this result. Consider the extreme case in which the L-globalization did not happen, i.e., $z_{I}=0$. The mean skill intensity of northern inputs is $\tilde{z}_{I I}=1 / 2$. Thus, if we keep the assumption that $\bar{z}=1 / 2$, the relative wage decreases from the onset of the C-globalization. Consider now the case in which there has been some Lglobalization, i.e., $z_{I}>0$. In this case, the mean skill is larger $\left(\tilde{z}_{I I}\left(z_{I}\right)>1 / 2\right)$, implying that the relative wage increases in the first stages of the C-globalization $\left(z_{I I}<\tilde{z}_{I I}\right)$, to decrease thereafter. This interdependence brings about the importance of taking into account the L-globalization to predict the effects of the C-globalization. There is a complementarity between trade in the two globalizations: northern wage polarization is delayed by the extent of trade in the L-globalization.

We provide suggestive evidence consistent with the complementarity result. Proposition 3 states that the deeper the L-globalization is, the more the relative wage of middle- to lowskill workers (our 50/10 measure) rises. Table 3 reports the results of regressing changes in northern 50/10 wage inequality on trade openness. ${ }^{21}$ The coefficient on trade openness is positive and significant (column 1), consistent with the complementarity result. This finding remains when controlling for income per capita (column 2) or restricting the sample to G-7 countries (column 3), obtaining very similar regression coefficients. Restricting the sample to G-7 countries and controlling for income per capita, yields a very similar coefficient on trade openness, although the coefficient is no longer significant at a $5 \%$ level.

Even though a quantitative assessment of the results presented in this section is beyond the scope of the paper, recent studies by Hummels et al. (2011) and by Ebenstein et al. (2011) find the effects of offshoring to be empirically relevant and heterogeneous across skill and "routine-intensiveness" in a manner consistent with the predictions of our model. For example, Hummels et al. (2011) find a wage-elasticity with respect to offshoring of around $3.3 \%$ and $-1.75 \%$ for agents with and without tertiary education, respectively. Ebenstein et al. (2011) find that "... for workers who are in occupations with the most routine content $(\ldots)$, a one percent increase in offshoring to low-income countries is associated with a 0.20 percent decrease in wages...." Finally, the estimates that we obtain from our complementarity result suggest a sizable effect of the complementarity between the two globalizations: a one percent increase in L-globalization trade, increases .2 points the relative wage of middle- to low-skill. Taken at face value, our regression explains around $30 \%$ percent of the variation in the changes in wage inequality in the 1990s.

\subsection{Two Souths and the Moving Band}

In this subsection, we investigate how the existence of different southern countries which asymmetrically participate in the C-globalization affects their pattern of specialization and wage inequality. As pointed out before, a key difference between the two globalizations

\footnotetext{
${ }^{21}$ Trade openness is computed as exports plus imports of the Northern countries to and from the South over GDP.
} 
is that, while the L-globalization is driven by trade liberalizations, the C-globalization is driven by the fall in communication costs. Arguably, a trade liberalization is a policy relatively easier to implement than building the specific capital needed to benefit from the IT revolution. Thus, it is reasonable to expect that not all southern countries can equally participate in the C-globalization. To account for this heterogeneity within our framework, we consider an extension in which two identical Souths, Southeast and Southwest, open asymmetrically to trade during the C-globalization. More specifically, we assume that the two Souths open to trade in the L-globalization, but only Southeast participates in the C-globalization. ${ }^{22}$

The equilibrium in the L-globalization is simple. Due to the symmetry of the two southern countries, all competitive equilibria feature the same wage schedule in both Souths. Appendix A contains the formal proof. We now turn to the characterization of the equilibrium in the C-globalization.

Proposition 4 (Pattern of Specialization) In the C-globalization, Southeast exports tasks $z \in\left[\bar{z}, z_{I I}\right]$ and intermediates $z \leq \check{z}_{I}\left(z_{I}, z_{I I}\right)$. Southwest exports intermediates $z \in\left[\check{z}_{I}\left(z_{I}, z_{I I}\right), z_{I}\right]$, with $0 \leq \check{z}_{I}\left(z_{I}, z_{I I}\right)<z_{I}$.

The reason for this result is that when Southeast starts offshoring tasks, its relative wage of low-skill workers decreases (these tasks are more skill-intensive than the intermediates offshored during the L-globalization). This gives Southeast comparative advantage in the least skill-intensive intermediates. As a result, in addition to tasks $\left(z \in\left[\bar{z}, z_{I I}\right]\right)$, Southeast also produces the least skill-intensive intermediates $\left(z \in\left[0, \check{z}_{I}\right]\right)$.

Proposition 5 (Moving Band) The threshold $\check{z}_{I}\left(z_{I}, z_{I I}\right)$ is increasing in $z_{I}$ and decreasing in $z_{I I}$ in the relevant range.

An implication of Proposition 5 is that the equilibrium tends to complete specialization as the C-globalization progresses (i.e., $z_{I I}$ increases). As the set of traded tasks increases, the labor demand in Southeast increases, raising wages. Thus, the range of intermediates in which Southwest has comparative advantage increases. Wages in Southeast rise and eventually reach a point in which Southeast is only able to produce tasks (i.e., $\check{z}_{I}$ goes to zero). Therefore, the band of intermediates produced in Southeast shrinks with the progress of the C-globalization. In this sense, we have a moving band of intermediates in which Southeast has comparative advantage.

In 2000, Internet access in India was twice as large as in Pakistan. If we take Internet access as a proxy for IT usage, this difference suggests an asymmetric participation in the C-globalization for India and Pakistan. ${ }^{23}$ Our model predicts India specializing in middleskill-intensive industries and Pakistan specializing in less skill-intensive industries. Figure

\footnotetext{
${ }^{22}$ We maintain Assumption 2.

${ }^{23}$ We use the number of Internet users per 100 inhabitants and the International Internet Bandwidth measured in bits per person from the World Development Indicators (World Bank). The relative supply of skills between India and Pakistan was similar in 1990 when compared to other developing countries. For example, according to the Barro-Lee data set, the fraction of agents with secondary education was $25 \%$ in India and $19 \%$ in Pakistan, for a $39 \%$ in Malaysia or a $34 \%$ in the Philippines.
} 
9 shows that Indian and Pakistani exports to the United States are consistent with this prediction. India increased exports in industries above the average skill requirement, and decreased exports in industries below. We analyze whether these results extend to a larger set of countries and run the following regression

$$
\Delta X_{i z}=\beta \Delta \text { Internet }_{i} \delta_{C(z)}+\gamma \Delta \operatorname{Internet}_{i} \delta_{L(z)}+\epsilon_{i z}
$$

where $\Delta X_{i z}$ denotes changes in exports from a southern country $i$ to the United States in industry $z$ between 2000 and 1990, $\Delta$ Internet $_{i}$ is Internet adoption in country $i$ in 2000, $\delta_{C(z)}$ is an indicator for industry $z$ participating in the C-globalization and $\delta_{L(z)}$ is an indicator for L-globalization industries. ${ }^{24}$ The prediction of our model is that as a southern country participates more in the C-globalization, it increases its exports in C-globalization goods, $\beta>0$, and reduces its exports in L-globalization goods, $\gamma<0$.

Column 1 of Table 4 reports the coefficients of our baseline regression. The interaction between Internet adoption and C-globalization industries is positive and significant and the interaction between Internet adoption and L-globalization industries is negative and also significant. In column 2 we reduce the number of industries participating in the Cglobalization by raising the RTI threshold from the 50th to the 66th percentile. The sign and significance of the coefficients remain the same. Therefore, the evidence presented in Table 4 is consistent with the prediction of the model.

Next, we characterize the behavior of relative wages.

Proposition 6 The relative wage of middle-skill workers is increasing in Southeast and (weakly) decreasing in Southwest in $z_{I I}$.

The intuition for this result is similar to Proposition 2. Southwest increases the production of intermediates below the mean skill of its domestic production, raising the relative wage of low-skill workers. The converse happens with Southeast. The set of exported tasks increases, while the band of exported intermediates decreases. As a result, the relative demand for middle-skill labor rises, thereby increasing its relative wage.

Proposition 6 highlights how gains from the C-globalization may not be equally shared between different types of workers across southern countries or, if we assume low labor mobility within countries, our model can be applied to different regions of the same country. In fact, some studies suggest that there is low labor mobility within southern countries. For example, Munshi and Rosenzweig (2009) document low labor mobility in rural India, even though inequality has risen in recent years. ${ }^{25}$ Then, this model could explain why

\footnotetext{
${ }^{24}$ There are no data for Internet adoption in 1990 and it was presumably negligible for most of sample. $\delta_{L(z)}=\left(1-\delta_{C(z)}\right) * \delta_{\text {low }(z)}$, where $\delta_{\text {low }(z)}$ is a dummy for industry $z$ taking value of one for industries below the average skill requirement. $\delta_{C(z)}$ is a dummy taking value of one for industry $z$ with the RTI index above the 50th and 66th percentile of the distribution in columns 1 and 2, respectively. Note that high levels of RTI are associated with middle-skill-intensive industries. The results we find (significant $\delta$ and $\gamma$ with the expected sign) are robust to adding as controls changes in income per capita and changes in access to domestic credit.

${ }^{25}$ Paweenawat and Townsend (2009) document a similar pattern for Thailand and show that wages are not equalized across different Thai regions. Candelaria et al. (2009) document a similar fact for China:
} 
inequality has increased in Bengaluru, an Indian city specialized in C-globalization exports, and declined in Bhopa, a city which has not benefited from C-globalization trade.

This section provided a tractable framework to study how differential access to trade generates changes in the pattern of specialization and wage inequality in otherwise identical southern countries. In our model, we assumed that the source of differential access to trade comes from the necessity of building an IT specific capital to benefit from the Cglobalization. We think of this infrastructure as being inherently more difficult to create and manage than tariff reductions. Therefore, our globalization approach provides a rationale for asymmetric participation within southern countries. This asymmetric participation generates a discontinuous pattern of specialization for the country (or region) participating in the C-globalization. It leads to increasing wage inequality in this country (or region), while reducing it in the one not participating.

\section{$5 \quad$ A Model with Endogenous Labor Supply}

In our baseline model we assumed that labor supply is exogenous. Therefore, we assumed that workers could not react to changes in the relative demand of skill. It could be argued that our assumption holds for unexpected labor demand shocks in the short-run but it becomes less realistic when considering longer periods of time. In order to address this concern, in this section we endogenize labor supply.

We extend the baseline model to allow agents to self-select in any of the occupations of the economy. Let $j$ be the index of an agent. We assume that $j \in[0,1]$. If agent $j$ chooses to be employed in a low-, middle- or high-skill job, this agent can supply one, $s^{i}(j)$ and $s^{i}(j)^{1+\varepsilon}$ units of labor in country $i$, respectively. $\varepsilon$ is some small number greater than zero. Note that wages described in Section 3 should now be interpreted as wages per unit of effective labor. To avoid a taxonomical analysis, we assume that functions $s^{i}(j)$ are strictly increasing.

North and South only differ on $s^{i}(j)$, where $s^{N}(j)$ first order stochastically dominates $s^{S}(j) \cdot{ }^{26}$ Note that there is a single-crossing property built in $s^{i}$. If an agent $j$ with skill $s^{i}(j)$ chooses to be employed as a high-skill worker, another agent $j^{\prime}$, with $j<j^{\prime}$ will also work as high-skill worker. Therefore, there exists a cutoff level of skill $\bar{s}^{i}$, such that all agents with $s^{i}>\bar{s}^{i}$ choose to work as high-skill workers. A similar reasoning applies for the middle to low decision.

The agent $\bar{j}^{i}$ in country $i$ who is indifferent between being employed in a middle- or low-skill job satisfies the condition $s^{i}(\bar{j}) w_{m}^{i}=w_{l}^{i}$. Similarly, the agent $\bar{J}$ who is indifferent between being employed in a high- or middle-skill job in the North verifies $s^{N}(\bar{J})^{\varepsilon} w_{h}^{N}=w_{m}^{N}$. It is convenient to choose a functional form for $s^{N}(j)$ to obtain analytic solutions. For tractability, we specialize $s^{N}(j)=j$ in what follows.

inequality in coastal regions has increased, while it has remained fairly constant in inland regions.

${ }^{26}$ Formally, this is $\frac{\int_{0}^{J} s^{N}(j) d j}{\int_{0}^{1} s^{N}(j) d j} \leq \frac{\int_{0}^{J} s^{S}(j) d j}{\int_{0}^{1} s^{S}(j) d j} \quad \forall J \in[0,1]$. 
Proposition 7 (L-globalization) During the L-globalization the mass of agents selecting into middle- and high-skill jobs increases with $z_{I}$ in the North. The relative wage of middleto low-skill workers and the relative wage of high-skill workers in the North increase with $z_{I}$. In the South, the mass of middle-skill workers and its relative wage increase with $z_{I}$.

The intuition for the results in Proposition 7 is that an increase in the set of tradeable intermediates increases the relative demand of middle-skill workers in both North and South. Therefore, the mass of agents selecting into middle-skill jobs increases in both countries. However, these changes in the supply of skills do not offset the primary demand forces, and the comparative statics for relative wages is analogous to section 4 . The return on high-skill labor increases with trade because it increases the set of intermediates that can be purchased in the South at a cheaper price, while the demand for low and middle-skill workers declines in the North.

Proposition 8 (C-globalization) During the C-globalization the equilibrium exhibits the following features. The mass of northern middle-skill workers increases for $z_{I I}<\tilde{z}_{I I}\left(z_{I}, \bar{z}\right)$ and decreases thereafter, where $\tilde{z}_{I I}\left(z_{I}, \bar{z}\right)$ is defined in Proposition 2. The mass of high-skill workers increases with $z_{I I}$. The mass of low-skill workers decreases for $z_{I I}<\tilde{z}_{I I}\left(z_{I}, \bar{z}\right)+$ $\eta\left(z_{I}, \bar{z}\right)$, with $\eta>0$ and increases thereafter. The relative wage of high-skill workers increases with $z_{I I}$ and the relative wage of middle-to low-skill workers increases for $z_{I I}<$ $\tilde{z}_{I I}\left(z_{I}, \bar{z}\right)+\eta\left(z_{I}, \bar{z}\right)$ and decreases thereafter. In the South, the mass of middle-skill workers and its relative wage increase with $z_{I I}$.

An implication of Proposition 8 is that wage polarization emerges during the C-globalization. Compared to the exogenous labor supply case, wage polarization is delayed when agents can endogenously select into occupations. This delay is intuitive because in the endogenous supply case there is an extra margin of adjustment. An additional insight from this exercise is to show the endogenous responses of the masses of agents selecting into each occupation. Consistent with the labor literature (e.g., Autor and Dorn, 2009), the mass of middle-skill workers in the North eventually shrinks and the mass of agents selecting low-skill jobs eventually expands with the C-globalization.

The results in this subsection suggest that from the point of view of the North, the L-globalization gave incentives to select into middle-skill jobs. In this sense, trade complemented middle skills during the L-globalization. However, this complementarity effect diminishes and it is eventually overturned as the C-globalization progresses and more skillintensive tasks are offshored to the South. In addition to a reduction in the relative wage of middle-skill workers, this generates a reduction in the mass of northern middle-skill agents. For the South, trade complements skills in both globalizations.

Finally, note that the results for the Two Souths stated in Subsection 4.2 hold in this extension of the model. The reason is that the relative wage of middle- to low-skill workers behaves in the same manner as in the baseline model and its behavior is what drives the results. 


\section{Concluding Remarks}

In this paper we provided a unified view of two globalization phases and analyzed their interdependence. We distinguished between different trade cost reductions, (i) trade liberalizations in the 1980s, which increased trade in low-skill-intensive goods (denoted LGlobalization) and (ii) reductions in communication costs due to the IT revolution, which raised trade in middle-skill-intensive goods during the 1990s (denoted C-Globalization).

We considered a North-South trade economy in which the North is skill-abundant. A final good is produced in the North employing high-skill agents and assembling a bundle of inputs. Inputs are produced combining middle- and low-skill labor in different proportions and can be purchased in the North or the South.

First, we analyzed the distributional effects of the globalization process. In the North, we showed that wage inequality increases during the L-globalization. In contrast, wage polarization emerges during the C-globalization. Our first main result highlighted the complementarity between the two globalizations. Wage polarization is delayed by the extent of L-globalization trade. We provided empirical evidence consistent with this result. We found a positive relationship between trade openness before the onset of the IT revolution and increases in lower-tail northern wage inequality in the 1990s. In the South, we showed that wage inequality increases in both globalizations.

Second, we studied asymmetric participation in the C-globalization amongst southern countries. We divided the original South in two identical southern countries and assumed that only one of the two southern countries could open to the C-globalization. Our second main result showed how this asymmetric trade participation generated a discontinuous pattern of specialization. The country that participates in the C-globalization exports C-globalization inputs and the least skill-intensive intermediates. As the C-globalization progresses, the set of L-globalization intermediates in which this country has comparative advantage shrinks, until complete specialization is reached. We provided evidence consistent with the prediction of the model. We showed that as southern countries raise their Internet adoption, they increase exports in RTI-intensive industries (C-globalization goods) and decrease exports in low-skill-intensive industries (L-globalization goods).

Finally, we allowed for endogenous labor supply choices. We showed that the comparative statics for relative wages hold in this generalized set-up. Moreover, we showed that the mass of northern agents selecting into middle-skill jobs increases during the L-globalization and eventually declines during the C-globalization, while the converse is true for the mass of agents selecting into low-skill jobs.

In this paper we have emphasized the role of the IT revolution in allowing firms to participate in the C-globalization. However, the C-globalization is also an outcome of the adoption of new technologies that replace middle- and low-skill jobs. Therefore, we think that an interesting extension of the two globalizations framework is to study the effect of trade on the adoption of new technologies. In an on-line appendix we show that the adoption of a new technology needed to benefit from C-globalization trade is delayed by 
the extent of trade in the L-globalization. We aim at pursuing this line of research to better understand the complementarities between technology adoption and international trade. Another research question which remains open and that has immediate policy implications is to try to quantify the effects of the trade channels we propose versus other explanations, such as immigration or pure technological change. 


\section{References}

Acemoglu, D. (1999). Changes in Unemployment and Wage Inequality: An Alternative Theory and Some Evidence. American Economic Review, 89(5):1259-1278.

Acemoglu, D. and Autor, D. (2012). What Does Human Capital Do? NBER Working Papers 17820, National Bureau of Economic Research, Inc.

Anderson, J. E. (2009). Globalization and Income Distribution: A Specific Factors Continuum Approach. NBER Working Papers 14643, National Bureau of Economic Research, Inc.

Anderson, J. E. and van Wincoop, E. (2004). Trade Costs. Journal of Economic Literature, $42(3): 691-751$.

Antràs, P., Garicano, L., and Rossi-Hansberg, E. (2006a). Offshoring in a Knowledge Economy. The Quarterly Journal of Economics, 121(1):31-77.

Antràs, P., Garicano, L., and Rossi-Hansberg, E. (2006b). Organizing Offshoring: Middle Managers and Communication Costs. NBER Working Papers 12196, National Bureau of Economic Research, Inc.

Attanasio, O., Goldberg, P. K., and Pavcnik, N. (2004). Trade reforms and wage inequality in Colombia. Journal of Development Economics, 74(2):331-366.

Autor, D. and Dorn, D. (2009). Inequality and Specialization: The Growth of Low-Skill Service Jobs in the United States. Working papers, MIT.

Autor, D., Dorn, D., and Hanson, G. (2011). The China Syndrome: Local Labor Market Effects of Import Competition in the United States. Mit working paper, MIT.

Autor, D. H., Katz, L. F., and Kearney, M. S. (2008). Trends in U.S. Wage Inequality: Revising the Revisionists. The Review of Economics and Statistics, 90(2):300-323.

Autor, D. H., Katz, L. F., and Krueger, A. B. (1998). Computing Inequality: Have Computers Changed The Labor Market? The Quarterly Journal of Economics, 113(4):11691213.

Autor, D. H., Levy, F., and Murnane, R. J. (2003). The Skill Content Of Recent Technological Change: An Empirical Exploration. The Quarterly Journal of Economics, 118(4):1279-1333.

Blinder, A. S. (2006). Offshoring: The Next Industrial Revolution? Foreign Affairs.

Blinder, A. S. and Krueger, A. B. (2009). Alternative Measures of Offshorability: A Survey Approach. Working Papers 1169, Princeton University, Department of Economics, Center for Economic Policy Studies. 
Candelaria, C., Daly, M., and Hale, G. (2009). Beyond Kuznets: persistent regional inequality in China. Working Paper 2009-07, Federal Reserve Bank of San Francisco.

Costinot, A. and Vogel, J. (2010). Matching and inequality in the world economy. Journal of Political Economy, 118(4):747-786.

Crinò, R. (2010). Service Offshoring and White-Collar Employment. Review of Economic Studies, 77(2):595-632.

Currie, J. and Harrison, A. E. (1997). Sharing the Costs: The Impact of Trade Reform on Capital and Labor in Morocco. Journal of Labor Economics, 15(3):S44-71.

Dinopoulos, E., Syropoulos, C., and Xu, B. (2009). Intraindustry Trade and Wage-Income Inequality. Working paper, University of Florida.

Dixit, A. K. and Grossman, G. M. (1982). Trade and Protection with Multistage Production. Review of Economic Studies, 49(4):583-94.

Ebenstein, A., Harrison, A., McMillan, M., and Phillips, S. (2011). Estimating the impact of trade and offshoring on american workers using the current population surveys. World Bank Policy Research Working Papers 5750, World Bank.

Feenstra, R. C. and Hanson, G. H. (1996). Foreign Investment, Outsourcing and Relative Wages. In Robert Feenstra, G. G. and Irwin, D., editors, The Political Economy of Trade Policy: Papers in Honor of Jagdish Bagwati. MIT Press.

Feenstra, R. C., Lipsey, R. E., Deng, H., Ma, A. C., and Mo, H. (2005). World Trade Flows: 1962-2000. NBER Working Papers 11040, National Bureau of Economic Research, Inc.

Goldberg, P. K. and Pavcnik, N. (2007). Distributional Effects of Globalization in Developing Countries. Journal of Economic Literature, 45(1):39-82.

Goos, M. and Manning, A. (2007). Lousy and Lovely Jobs: The Rising Polarization of Work in Britain. The Review of Economics and Statistics, 89(1):118-133.

Grossman, G. M. and Maggi, G. (2000). Diversity and Trade. American Economic Review, 90(5):1255-1275.

Grossman, G. M. and Rossi-Hansberg, E. (2006). The rise of offshoring: it's not wine for cloth anymore. Proceedings, pages 59-102.

Grossman, G. M. and Rossi-Hansberg, E. (2008). Trading Tasks: A Simple Theory of Offshoring. American Economic Review, 98(5):1978-97.

Hanson, G. H. and Harrison, A. (1999). Trade liberalization and wage inequality in Mexico. Industrial and Labor Relations Review, 52(2):271-288.

Haskel, J. E. and Slaughter, M. J. (2003). Have Falling Tariffs and Transportation Costs Raised US Wage Inequality? Review of International Economics, 11(4):630-650. 
Hummels, D. (2007). Transportation Costs and International Trade in the Second Era of Globalization. Journal of Economic Perspectives, 21(3):131-154.

Hummels, D., Jrgensen, R., Munch, J. R., and Xiang, C. (2011). The Wage Effects of Offshoring: Evidence from Danish Matched Worker-Firm Data. Working Paper 17496, National Bureau of Economic Research.

Katz, L. F. and Murphy, K. M. (1992). Changes in Relative Wages, 1963-1987: Supply and Demand Factors. The Quarterly Journal of Economics, 107(1):35-78.

Liu, R. and Trefler, D. (2011). A Sorted Tale of Globalization: White Collar Jobs and the Rise of Service Offshoring. NBER Working Papers 17559, National Bureau of Economic Research, Inc.

Markusen, J. (2006). Offshoring of Business Services in Small Open Economies: Toward a General-Equilibrium Modeling Approach. Brookings Trade Forum 2005: Offshoring White-Collar Work.

Markusen, J. and Strand, B. (2008). Offshoring of Business Services in Small Open Economies: Toward a General-Equilibrium Modeling Approach. Journal of Industry, Competition and Trade, 8(3):231-246.

Munshi, K. and Rosenzweig, M. (2009). Why is Mobility in India so Low? Social Insurance, Inequality, and Growth. Working Paper 14850, National Bureau of Economic Research.

Ohnsorge, F. and Trefler, D. (2007). Sorting It Out: International Trade with Heterogeneous Workers. Journal of Political Economy, 115(5):868-892.

Oldenski, L. (2011). The Task Composition of Offshoring by US Multinationals. Mimeo, Georgetown University.

Oldenski, L. (2012). Offshoring and the Polarization of the US Labor Market. Mimeo, Georgetown University.

Paweenawat, A. and Townsend, R. M. (2009). Villages as Small Open Economies. Working paper, MIT.

Robertson, R. (2000). Trade Liberalisation and Wage Inequality: Lessons from the Mexican Experience. The World Economy, 23(6):827-849.

Robertson, R. (2004). Relative prices and wage inequality: evidence from Mexico. Journal of International Economics, 64(2):387-409.

Topalova, P. (2005). Trade Liberalization, Poverty, and Inequality: Evidence from Indian Districts. NBER Working Papers 11614, National Bureau of Economic Research, Inc.

Trefler, D. (2006). Service Offshoring: Threats and Opportunities. Brookings Trade Forum 2005: Offshoring White-Collar Work. 
Wood, A. (1995). How Trade Hurt Unskilled Workers. The Journal of Economic Perspectives, $9(3): 57-80$.

Zhu, S. C. and Trefler, D. (2005). Trade and inequality in developing countries: a general equilibrium analysis. Journal of International Economics, 65(1):21-48. 


\section{A Proofs and Auxiliary Propositions}

Proof of Proposition 2 Using equations (11) to (14) and the trade cost structure, (17), the relative wages of middle-skill workers are

$$
\begin{aligned}
\frac{w_{h}^{N}}{w_{m}^{N}} & =\frac{1-\varphi}{\varphi} \frac{\alpha}{1-\alpha} \frac{2}{1-z_{I}^{2}-z_{I I}^{2}+\bar{z}^{2}}, \\
\frac{w_{m}^{N}}{w_{l}^{N}} & =\frac{1-z_{I}^{2}-z_{I I}^{2}+\bar{z}^{2}}{\left(1-z_{I}\right)^{2}+\left(1-z_{I I}\right)^{2}-(1-\bar{z})^{2}} \frac{1-\theta^{N}}{\theta^{N}(1-\varphi)}, \\
\frac{w_{m}^{S}}{w_{l}^{S}} & =\frac{z_{I}^{2}+z_{I I}^{2}-\bar{z}^{2}}{1-\left(1-z_{I}\right)^{2}-\left(1-z_{I I}\right)^{2}+(1-\bar{z})^{2}} \frac{1-\theta^{S}}{\theta^{S}} .
\end{aligned}
$$

The relative wage of high skill workers in the North increases with $z_{I I}$ because the denominator decreases with $z_{I I}$. Note that the same reasoning applies for the relative wage of high- to low-skill workers. Taking the partial derivative of the relative wage of middle-skill workers (19) in the North, we find that it is increasing in $z_{I I}$ as long as $z_{I I}<\tilde{z}_{I I}\left(z_{I}\right) \equiv$ $1+\bar{z}-z_{I}-\sqrt{2\left(\bar{z}-z_{I}\right)\left(1-z_{I}\right)}$. For the relative wage in the South, the sign of the partial derivative with respect to $z_{I I}$ is always positive.

Proof of Proposition 3 Direct differentiation of $\tilde{z}_{I I}\left(z_{I}\right)$ yields to

$$
2 \frac{1-2 z_{I}+\bar{z}}{\sqrt{2\left(\bar{z}-z_{I}\right)\left(1-z_{I}\right)}}-1
$$

This expression is positive, and hence $\tilde{z}_{I I}\left(z_{I}\right)$ increasing in $z_{I I}$. To see this, note that $(21)$ is positive if and only if

$$
2\left(\frac{1}{\bar{z}-z_{I}}+\frac{1}{1-z_{I}}\right)>1
$$

which is true because both fractions are greater than one.

Proposition 9 In the two Souths model of Subsection 4.2, all competitive equilibria in the L-globalization have the same wage schedule for both Souths.

Proof First, note that the price function in country $i$ is a geometric mean of the middleand low-skill wages. The price schedule in a country $i, p^{i}(z)$, is strictly monotone in $z$ (if the wages of middle- and low-skill agents are different). Thus the price functions can cross at most once.

We proof the result by contradiction. Note that in autarky, the price of intermediates were the same in both Souths (because both are identical) and that as a result of opening to trade, the prices in the South strictly increase if there is positive demand from the North in any good. Suppose that North demands the set of goods $\chi_{1}$ to Southeast and $\chi_{2}$ to Southwest, where we are allowing for some traded intermediates $z \notin \chi_{1} \cap \chi_{2}$. Note that intermediate $z=0$ has to be produced only by one country, because otherwise the price in both countries would be the same and by single crossing we cannot have an equilibrium. Suppose Southeast produces it. To have an equilibrium we must have the prices crossing in 
the relevant range. This means that $w_{l}^{\text {Southeast }}<w_{l}^{\text {Southwest }}$ and that $w_{m}^{\text {Southeast }}>w_{m}^{\text {Southwest }}$. In other words, the relative demand of middle-skill workers in Southeast is higher than in Southwest. This implies that intermediates with low index $z$ (low means below the threshold at which the two prices cross) are cheaper in Southeast and yet there is more demand of them in Southwest. This is a contradiction, unless both prices are equal, which implies that wages are equal in Southeast and Southwest.

Proof of Proposition 4 For algebraic convenience we normalize the population size of each southern country to one. Let $f(z)$ denote the fraction of each intermediate $z$ produced by Southeast in the range $z \in\left[0, z_{I}\right]$. Thus, Southwest produces the remaining fraction $1-f(z)$. Prices in both Souths will generically coincide if and only if wages of middleskill and low-skill workers are equalized in equilibrium. Denoting $E_{f}[z]=\int_{0}^{z_{I}} z f(z) d z$, equalization of middle-skill wages implies that $E_{f}[z]=\frac{1}{2} \int_{0}^{z_{I}} z d z$. Equalization of low-skill wages implies that $E_{f}[z]=1-\frac{1}{2} \int_{0}^{z_{I}}(1-z) d z$. This two conditions cannot be satisfied at the same time, and thus, the price schedule will be different in Southeast and Southwest.

By an analogous reasoning of Proposition 9, prices can cross at most once. Thus, there is a threshold equilibrium. Denote by $\check{z}_{I}$ the threshold intermediate. We show the result by contradiction. Suppose that Southwest produces $z \in\left[0, \check{z}_{I}\right]$ and that Southeast produces $z \in\left[\check{z}_{I}, z_{I}\right] \cup\left[\bar{z}, z_{I I}\right]$. This can be an equilibrium if and only if $w_{l}^{\text {Southwest }}<w_{l}^{\text {Southeast }}$ and $w_{m}^{\text {Southwest }}>w_{m}^{\text {Southeast }}$. These conditions on wages imply

$$
\begin{aligned}
& 0< z_{I}\left(1-\frac{z_{I}}{2}\right)-2 \check{z}_{I}\left(1-\frac{\check{z}_{I}}{2}\right)+z_{I I}\left(1-\frac{z_{I I}}{2}\right)-\bar{z}_{I}\left(1-\frac{\bar{z}_{I}}{2}\right) \\
& 0<2 \check{z}_{I}^{2}-z_{I}^{2}-z_{I I}^{2}+\bar{z}_{I}^{2}
\end{aligned}
$$

which cannot be satisfied simultaneously. Thus this cannot be an equilibrium.

Proof of Proposition 5 The threshold $\check{z}_{I}$ can be expressed implicitly as the solution to the problem $p_{\text {Southeast }}(z)=p_{\text {Southwest }}(z)$ for some $z \in\left[0, z_{I}\right]$, where if the equality is not satisfied, then either 0 or $z_{I}$ is the solution, depending on whether the price schedule of Southeast is above or below the price schedule of Southwest for $z \in\left[0, z_{I}\right]$. Using that in order to have an equilibrium middle-skill wages are higher in Southeast and low-skill wages are lower in Southeast, we have that the geometric average with parameter $z$

$$
\left(\frac{w_{m}^{\text {Southeast }}}{w_{m}^{\text {Southwest }}}\right)^{z}\left(\frac{w_{l}^{\text {Southeast }}}{w_{l}^{\text {Southwest }}}\right)^{1-z}
$$

will be exactly one by some $z$ between zero and one. Consider an interior solution for $z$. Inspection of the explicit equation (22) shows that both the ratios of middle-skill and low-skill wages in Southeast to Southwest are decreasing in $z_{I}$ and increasing in $z_{I I}$ and $\check{z}_{I}$. As result, and using implicit derivation, it follows that in this range $\breve{z}_{I}\left(z_{I}, z_{I I}\right)$ is increasing in $z_{I}$ and decreasing in $z_{I I}$. Letting $A \equiv \frac{w_{m}^{\text {Southeast }}}{w_{m}^{\text {Southwest }}}$ and $B \equiv \frac{w_{l}^{\text {Southeast }}}{w_{l}^{\text {Southwest }}}$, the expression for the 
implicit derivatives of $\check{z}_{I}$ becomes, after some manipulation,

$$
\frac{\partial \check{z}_{I}}{\partial z_{i}}\left[\ln A-\ln B+\frac{\check{z}_{I}}{A} \frac{\partial A}{\partial \check{z}_{I}}+\frac{\left(1-\check{z}_{I}\right)}{B} \frac{\partial B}{\partial \check{z}_{I}}\right]=-\frac{\check{z}_{I}}{A} \frac{\partial A}{\partial z_{i}}-\frac{\left(1-\check{z}_{I}\right)}{B} \frac{\partial B}{\partial z_{i}}
$$

where $i=\{I, I I\}$. The sign of the term in brackets in the left hand side is positive for all $i$ and the term on the right hand side is positive for $z_{I}$ and negative for $z_{I I}$. Thus, the sign of the derivative of the threshold $\check{z}_{I}$ with respect to $z_{i}$ is unambiguous.

Proof of Proposition 6 The relative wages in Southeast and Southwest are proportional to

$$
\frac{w_{m}^{\text {Southeast }}}{w_{l}^{\text {Southeast }}} \propto \frac{\check{z}_{I}^{2}+z_{I I}^{2}-\bar{z}^{2}}{1-\left(1-\check{z}_{I}\right)^{2}-\left(1-z_{I I}\right)^{2}+(1-\bar{z})^{2}}, \quad \frac{w_{m}^{\text {Southwest }}}{w_{l}^{\text {Southwest }}} \propto \frac{z_{I}^{2}-\check{z}_{I}^{2}}{\left(1-\check{z}_{I}\right)^{2}-\left(1-z_{I}\right)^{2}} .
$$

From Proposition 5, the relative wage in Southwest is decreasing in $z_{I I}$ for the range in which there is an interior solution for $\check{z}_{I}$ and is constant otherwise. For the relative wage in Southeast, if $\check{z}_{I}=0$, it is immediate to check that the relative wage is increasing in $z_{I I}$. If $\check{z}_{I}>0$, we first show that a sufficient condition for the relative wage being increasing is that $\left|\partial \check{z}_{I} / \partial z_{I I}\right|<1$. If this is the case, the change induced in $\check{z}_{I}$ by an infinitesimal change $\varepsilon$ in $z_{I I}$ is bounded below by $z_{I}-\varepsilon$. Algebraic manipulation shows that as long as $z_{I I}>\check{z}_{I}$ (which is true by assumption), the relative wage is increasing in $z_{I I}$.

To show that $\left|\partial \check{z}_{I} / \partial z_{I I}\right|<1$, we show that an upper bound of this derivative is less than one,

$$
\frac{\frac{\check{z}_{I}}{A} \frac{\partial A}{\partial z_{I I}}+\frac{\left(1-\check{z}_{I}\right)}{B} \frac{\partial B}{\partial z_{I I}}}{\frac{\check{z}_{I}}{A} \frac{\partial A}{\partial \check{z}_{I}}+\frac{\left(1-\check{z}_{I}\right)}{B} \frac{\partial B}{\partial \check{z}_{I}}}<1 .
$$

This condition reduces to

$$
\frac{-2 \check{z}_{I} z_{I}+z_{I}+\check{z}_{I}}{\left(z_{I}-\check{z}_{I}\right)\left(z_{I}+\check{z}_{I}-2\right)\left(z_{I}+\check{z}_{I}\right)}+\frac{\check{z}_{I}\left(z_{I I}-\check{z}_{I}\right)}{\check{z}_{I}^{2}+z_{I I}^{2}-\bar{z}^{2}}+\frac{\left(\check{z}_{I}-1\right)\left(\check{z}_{I}-z_{I I}\right)}{\left(\check{z}_{I}-2\right) \check{z}_{I}+\left(z_{I I}-\bar{z}\right)\left(z_{I I}+\bar{z}-2\right)}<0,
$$

which is true given that $0<\check{z}_{I}<z_{I}<\bar{z} \leq z_{I I}<1$.

Proof of Proposition 7 The indifference conditions can be rewritten as

$$
\begin{aligned}
\bar{J}^{\varepsilon} \frac{\alpha}{1-\alpha} \frac{(2+\varepsilon)}{1-\bar{J}^{2+\varepsilon}} & =\frac{1-z_{I}^{2}-z_{I I}^{2}+\bar{z}^{2}}{\bar{J}^{2}-\bar{j}^{N^{2}}} \\
\bar{j}^{N} \frac{1-z_{I}^{2}-z_{I I}^{2}+\bar{z}^{2}}{\bar{J}^{2}-\bar{j}^{N^{2}}} & =\frac{\left(1-z_{I}\right)^{2}+\left(1-z_{I I}\right)^{2}-(1-\bar{z})^{2}}{2 \bar{j}^{N}} \\
\bar{s}^{S}\left(\bar{j}^{S}\right) \frac{z_{I}^{2}+z_{I I}^{2}-\bar{z}^{2}}{\int_{\bar{j}^{S}}^{1} s^{S}(j) d j} & =\frac{1-\left(1-z_{I}\right)^{2}-\left(1-z_{I I}\right)^{2}+(1-\bar{z})^{2}}{\bar{j}^{S}} .
\end{aligned}
$$

Consider the case for the South. Equation (26) can be rewritten as

$$
\frac{\int_{\bar{j}^{S}}^{1} s^{S}(j) d j}{2 \bar{j}^{S} \bar{s}^{S}\left(\bar{j}^{S}\right)}=\frac{\theta^{S}}{\left(1-\theta^{S}\right)} \frac{w_{m}^{S}}{w_{l}^{S}},
$$


where the expression for the wages corresponds to section 4 . Thus, the right hand side of equation (27) is increasing in $z_{I}$. The left hand side of (27) is decreasing in $\bar{j}^{S}$. Therefore, $\bar{j} S$ is decreasing in $z_{I}$. Note that the relative wage of a middle-skill agent can be written as

$$
\frac{w_{m}^{S}}{w_{l}^{S}}=\frac{s^{S}(j)}{s^{S}\left(\bar{j}^{S}\left(z_{I}\right)\right)} .
$$

Thus, the relative wage in the South increases with $z_{I}$.

Consider the case for the North. Given that $\varepsilon$ is a small positive number, we assume that $2+\varepsilon \approx 2$. Under this simplifying assumption, we find

$$
\begin{aligned}
\bar{J}^{2} & =\frac{(1+A) C}{1+(1+A) C}, \\
\bar{j}^{N^{2}} & =\frac{A C}{1+(1+A) C},
\end{aligned}
$$

where $A=\frac{\left(1-z_{I}\right)^{2}+\left(1-z_{I I}\right)^{2}-(1-\bar{z})^{2}}{2\left(1-z_{I}^{2}-z_{I I}^{2}+\bar{z}^{2}\right)}$ and $C=\frac{(1-\alpha)}{\alpha} \frac{1-z_{I}^{2}-z_{I I}^{2}+\bar{z}^{2}}{2}$. In the L-globalization $z_{I I}=\bar{z}$, thus, $A$ and $C$ (and $A C$ ) are decreasing in $z_{I}$. Therefore, $\bar{J}$ and $\bar{j}^{N}$ are decreasing in $z_{I}$. Finally, note that the size of middle agents is

$$
\frac{\bar{J}}{\bar{j}^{N}}=\sqrt{\frac{1+A}{A}},
$$

which increases in the L-globalization. Finally, relative wages are

$$
\begin{aligned}
\frac{w_{h}^{N}}{w_{m}^{N}} & =\frac{j^{1+\epsilon}}{\bar{J}^{\epsilon}\left(z_{I}\right)}, \\
\frac{w_{m}^{N}}{w_{l}^{N}} & =\frac{j}{\bar{j}^{N}\left(z_{I}\right)},
\end{aligned}
$$

which are increasing in $z_{I}$.

Proof of Proposition 8 For the South, the same reasoning as in Proposition 7 applies. For the North, the comparative statics are as in Proposition 7, while $A$ is decreasing. However, when $z_{I I}>\tilde{z}_{I I}\left(z_{I}\right), A$ increases. From equation (31), it follows that the mass of middle- skill workers declines. The comparative statics for the mass of high-skill workers does not depend on $A$, but on $A C$, which is unambiguously decreasing in $z_{I I}$. From equation (29), this implies that the threshold $\bar{J}$ is decreasing in $z_{I I}$. From equation (32), this implies that the relative wage of high skill agents is increasing. The threshold $\bar{j}^{N}$ is implicitly defined by equation (30). Taking the total derivative of (30) with respect to $z_{I I}$, we can isolate $d \bar{j}^{N} / d z_{I I}$. Evaluating this derivative at $z_{I I}=\bar{z}$ and $z_{I I}=1$, shows that the derivative takes negative and positive values, respectively. Moreover, it is immediate to check that the derivative is continuous and monotone. Intuitively, monotonicity follows from the derivatives of $A$ and $C$ being monotone. Thus, by the Bolzano theorem, we know that there is a unique threshold for $z_{I I}$, above which $d \bar{j}^{N} / d z_{I I}>0$. Note that this threshold is above $\tilde{z}_{I I}$ (defined in Proposition 2) because $\partial A /\left.\partial z_{I I}\right|_{I I}=\tilde{z}_{I I}=0$, and from the implicit 
derivation of equation (30), it follows that $d \bar{j}^{N} /\left.d z_{I I}\right|_{z_{I I}=\tilde{z}_{I I}}<0$.

\section{B Data Appendix}

World bilateral trade flows are taken from Feenstra database, Feenstra et al. (2005). We obtain U.S. tariff data at industry level for the period 1978-1988 from Feenstra database. Feenstra's data is available from http://cid.econ.ucdavis.edu/. For the period 1990-2000, we use Romalis database, available at http://faculty.chicagobooth.edu/john.romalis/more/. Transportation costs are cost of insurance and freight over customs import value from Feenstra database. Data on U.S. imports comes from Feenstra database.

We construct a skill intensity index by using 5 percent U.S. census data from IPUMS. The skill intensity variable is constructed assigning a score to each level of education reported in the US Census, using the variable educ99. We average across industries by same NAICS and across occupations when noted in the main text.

We take the routine-intensity index (RTI) from Autor and Dorn (2009). Roughly speaking, using the Dictionary of Tasks each task can be divided into three characteristics (abstract, routine and manual) and it is assigned a score for each of the three entries. The RTI index represents the importance of the routine part for each task. See Autor and Dorn (2009) for further discussion.

Internet measures are obtained from the World Development Indicators (WDI), available from the World Bank. For the robustness checks, the financial development measure is domestic credit to private sector over GDP. Human capital is the fraction of the labor force with secondary education. Both measures are obtained from the World Development Indicators (WDI). 
C Tables and Figures 


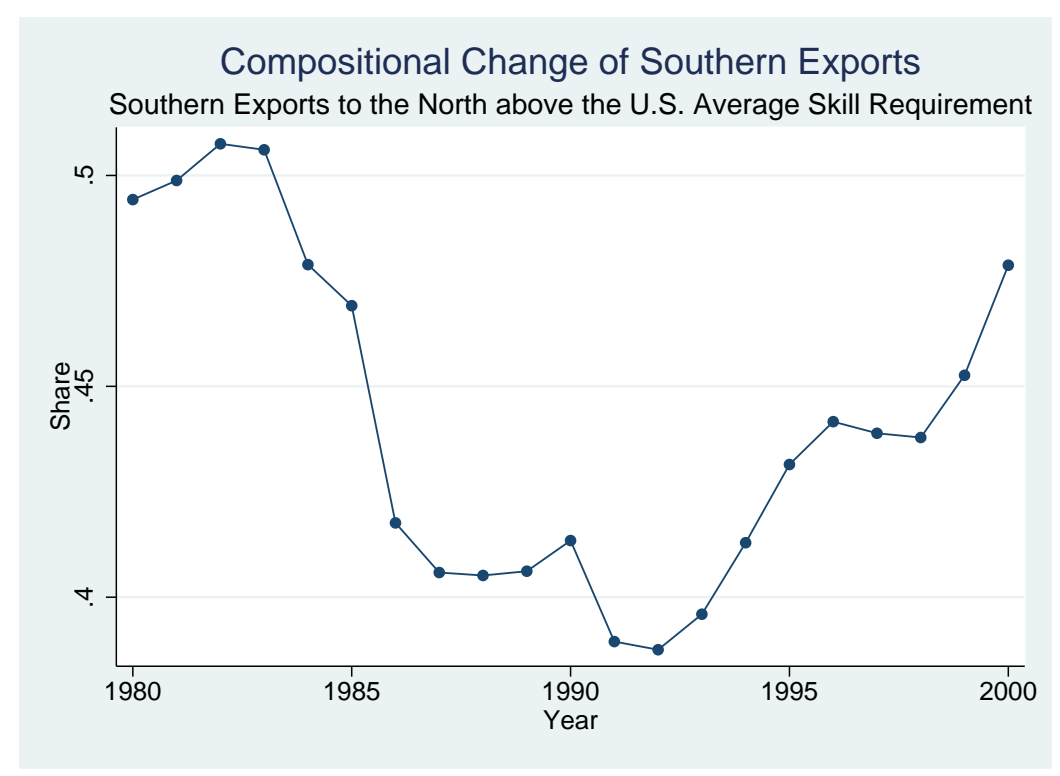

Figure 1: Changes in southern exports to the North in industries with above average U.S. skill intensity. The mean skill intensity of U.S. industries is measured using educational attainment in U.S. Census. North is defined as having more than 50 percent of U.S. GDP per capita (PPP adjusted). Source: Feenstra World Trade Database. Note that data pre- and post-1984 come from different sources (Feenstra et al., 2005).

Table 1: Trade Costs and Pattern of Specialization

\begin{tabular}{|c|c|c|c|c|c|c|}
\hline & (1) & (2) & (3) & (4) & (5) & (6) \\
\hline & \multicolumn{3}{|c|}{ Whole Sample } & \multicolumn{3}{|c|}{ South } \\
\hline & OLS & OLS & $2 \mathrm{SLS}$ & OLS & OLS & 2 SLS \\
\hline & Panel & : Depen & ent Vari & is U.S. & $\overline{\text { Imports i }}$ & $n 1990$ \\
\hline Tariff & $\begin{array}{l}-6.77 \\
(2.31)\end{array}$ & & & $\begin{array}{l}-8.20 \\
(2.56)\end{array}$ & & \\
\hline \multirow[t]{2}{*}{ Observations } & 26397 & & & 12642 & & \\
\hline & Panel & : Depen & ent Vari & is U.S. & Imports i & n2000 \\
\hline Tariff & $\begin{array}{l}-3.46 \\
(2.47)\end{array}$ & $\begin{array}{l}-4.07 \\
(2.43)\end{array}$ & $\begin{array}{l}-4.05 \\
(3.62)\end{array}$ & $\begin{array}{l}-1.29 \\
(2.88)\end{array}$ & $\begin{array}{l}-1.49 \\
(2.89)\end{array}$ & $\begin{array}{l}-1.48 \\
(2.57)\end{array}$ \\
\hline Internet · Skill Intensity & & $\begin{array}{c}6.30 \\
(5.03)\end{array}$ & $\begin{array}{l}6.09 \\
(.93)\end{array}$ & & $\begin{array}{c}9.59 \\
(2.66)\end{array}$ & $\begin{array}{c}8.07 \\
(1.64)\end{array}$ \\
\hline Observations & 262303 & 261961 & 261961 & 126891 & 126549 & 126549 \\
\hline
\end{tabular}

Standard errors are clustered by country in the OLS regressions, robust standard errors in the 2SLS. A southern country is defined as having less than half of 2000 U.S. GDP per capita adjusted by PPP from the Penn World Tables. RTI index is used as instrument of Skill Intensity in the first stage regressions, which are omitted. All regressions include country and industry fixed effects. Dependent variable is U.S. Imports from Feenstra's NBER Dataset. Tariff is U.S. Tariffs at HS6 level from Romalis' Dataset. Skill intensity is mean level of education from U.S. Census for industry. Internet is the fraction of population with access to Internet in 2000. See Appendix B for detailed data definitions and sources. 
Table 2: Change in Trade Openness and Wage Bill in the U.S.

\begin{tabular}{|c|c|c|c|}
\hline & (1) & $(2)$ & (3) \\
\hline & $\Delta$ Wage Bill 80-90 & \multicolumn{2}{|c|}{$\Delta$ Wage Bill 90-96 } \\
\hline$\Delta$ Trade Openness $80-90 \cdot$ Skill Int. & $\begin{array}{l}1.65 \\
(.43)\end{array}$ & & \\
\hline$\Delta$ Trade Openness $90-96 \cdot$ Skill Int. & & $\begin{array}{c}.29 \\
(.17)\end{array}$ & $\begin{array}{l}-4.62 \\
(2.17)\end{array}$ \\
\hline$\Delta$ Trade Openness $90-96 \cdot$ Skill Int. ${ }^{2}$ & & & $\begin{array}{l}.23 \\
(.10)\end{array}$ \\
\hline Observations & 118 & 118 & 118 \\
\hline
\end{tabular}

Robust Standard Errors in parenthesis. $\Delta$ Trade Openness is the change in the share of exports and imports over GDP from the Penn World Tables. Wage bill data at industry level at 3-digit NAICS comes from Autor et al. (1998). Skill intensity is the mean level of education from U.S. Census by industry.

Table 3: Complementarity in the North

\begin{tabular}{lcccc}
\hline \hline & $(1)$ & $(2)$ & $(3)$ & $(4)$ \\
\hline & \multicolumn{2}{l}{ Whole Sample } & & \multicolumn{3}{c}{ G-7 Countries } \\
\cline { 2 - 5 } \cline { 3 - 4 } Dep. & Var.: Change & in $50 / 10$ & wage in the 1990s \\
\hline \multirow{2}{*}{ Trade Openness 1990 } & .22 & .20 & .22 & .24 \\
Income per capita & $(.09)$ & $(.10)$ & $(.08)$ & $(.15)$ \\
& & -.005 & & .003 \\
Observations & & $(.01)$ & & $(.02)$ \\
\hline \hline
\end{tabular}

Robust Standard Errors in parenthesis. All regressions include an intercept. The change in $50 / 10$ wage inequality comes from the LIS data, to which we add Japan from the OECD. We restrict the LIS sample to countries that have more than $50 \%$ of U.S. income per capita. The LIS data are taken from rounds V and III. Trade Openness of a Northern country is defined as the share of exports to and imports from Southern countries over GDP from the Penn World Tables in 1990. The income per capita data are taken from Penn World Tables for 1995. Since we do not have data for Germany prior 1991, we use data for trade openness in 1991 instead of 1990 for Germany. 
Table 4: Testing the Moving Band

\begin{tabular}{|c|c|c|}
\hline & $(1)$ & $(2)$ \\
\hline & Dep. & Var.: $\Delta \operatorname{Imp}$. \\
\hline$\Delta$ Internet $\delta_{C(z)}$ & $\begin{array}{c}.053 \\
(.015)\end{array}$ & $\begin{array}{c}.091 \\
(.025)\end{array}$ \\
\hline$\Delta$ Internet $\delta_{L(z)}$ & $\begin{array}{c}-.049 \\
(.013)\end{array}$ & $\begin{array}{c}-.047 \\
(.012)\end{array}$ \\
\hline Obs. & 1705 & 1705 \\
\hline
\end{tabular}

Standard errors are clustered by country. All regressions include an intercept. Dependent variable is change in U.S. southern imports between 1990 and 2000. U.S. Imports data are from Feenstra's NBER Dataset. $\triangle$ Internet is the fraction of the population with access to Internet in 2000. There are no data for Internet adoption in 1990 and it was presumably negligible for most of the sample. $\delta_{L(z)}=\left(1-\delta_{C(z)}\right) * \delta_{\text {low }(z)}$, where $\delta_{\text {low }(z)}$ is a dummy for industry $z$ taking value of one for industries below the average skill requirement. $\delta_{C(z)}$ is a dummy taking value of one for industry $z$ with the RTI index above the 50th and 66th percentile of the distribution in columns 1 and 2, respectively. A southern country is defined as having less than 50 percent of U.S. GDP per capita (PPP adjusted). See the Appendix B for detailed data definitions and sources.

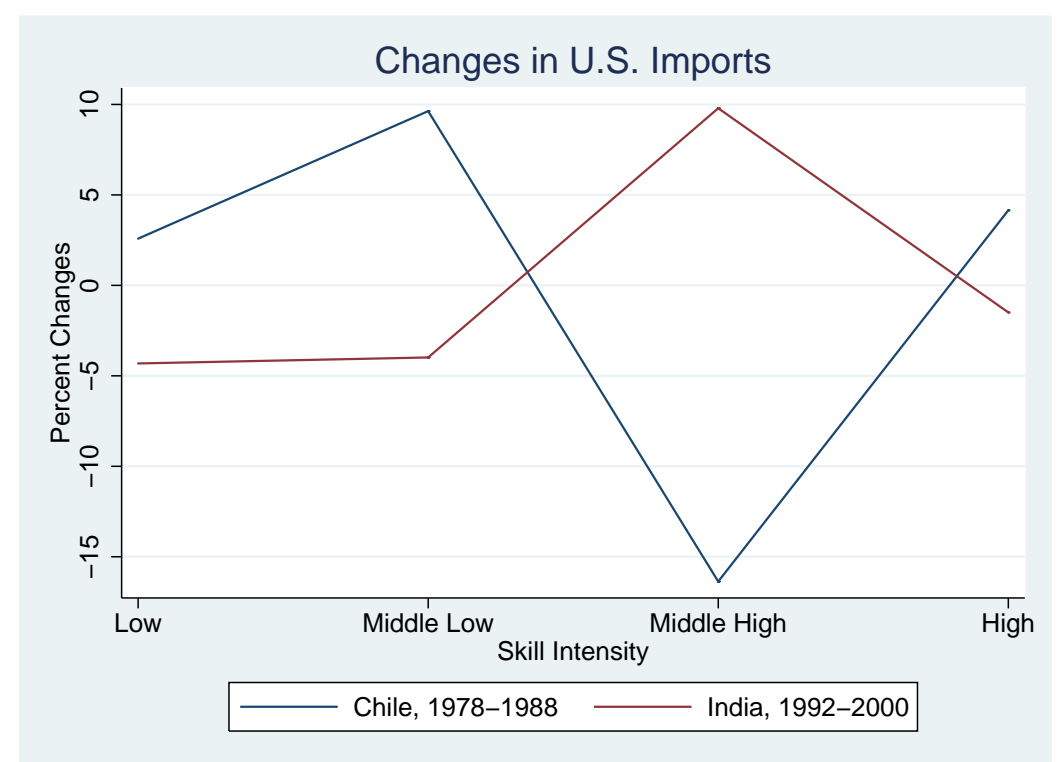

Figure 2: Changes in U.S. imports from India and Chile for different skill levels. For comparability with our tariff data, we can only consider the period 1978-1988 for the L-Globalization. For India, the series starts in 1992 to dampen the effect of the trade liberalization in 1991, documented in Topalova (2005) among others. Source: Feenstra U.S. Imports Database, Skill Intensity constructed from U.S. Census. 


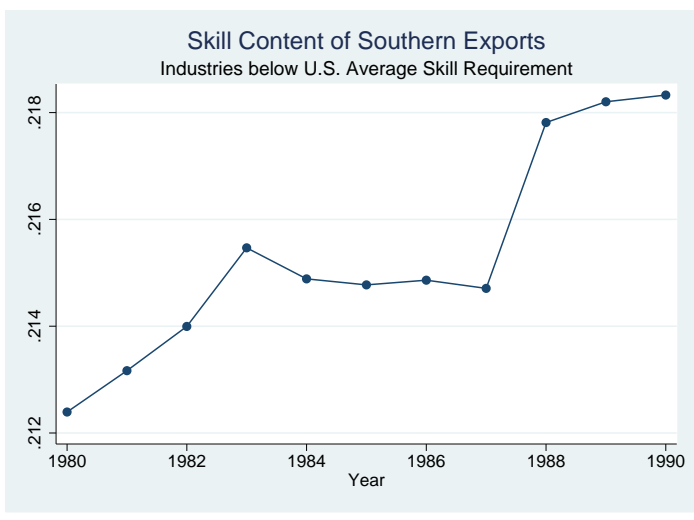

(a) Skill Content of Southern Exports in industries with skill requirement below U.S. average.

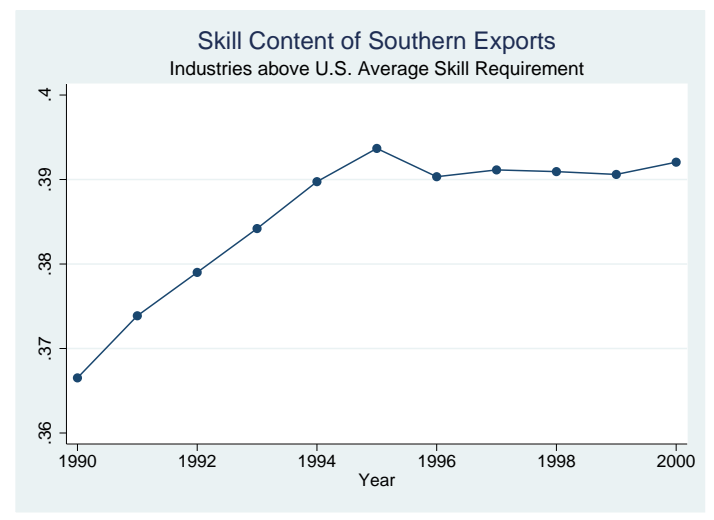

(b) Skill Content of Southern Exports in industries with skill requirement above U.S. average.

Figure 3: Skill Content of Southern Exports. The skill content is the weighted average of the skill embodied in southern exports. The skill intensity of U.S. industries is measured using educational attainment in U.S. Census. North is defined as having more than 50 percent of U.S. GDP per capita (PPP adjusted). Source: Feenstra World Trade Database.

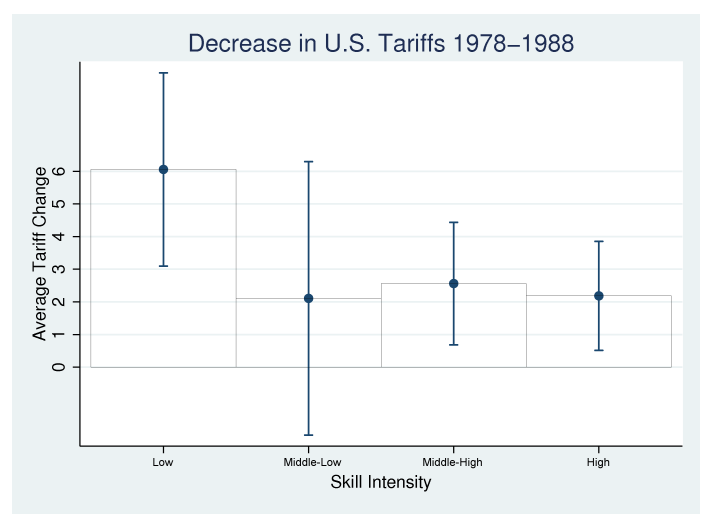

(a) Changes in U.S. Tariffs by Skill in the LGlobalization. (Two Std. Dev. bars). Source: Feenstra tariff data.

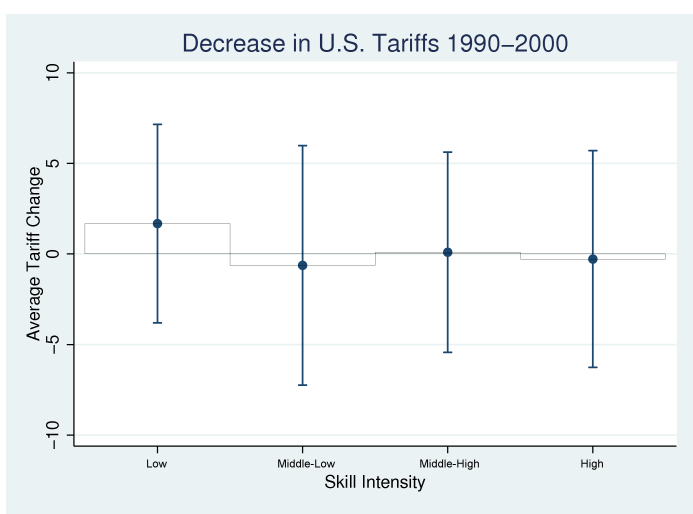

(b) Changes in U.S. Tariffs by Skill in the CGlobalization. (One Std. Dev. bars). Source: Romalis tariff data.

Figure 4: Changes in U.S. Tariffs by Skill.Source: Feenstra database for panel A and Romalis database for panel B.
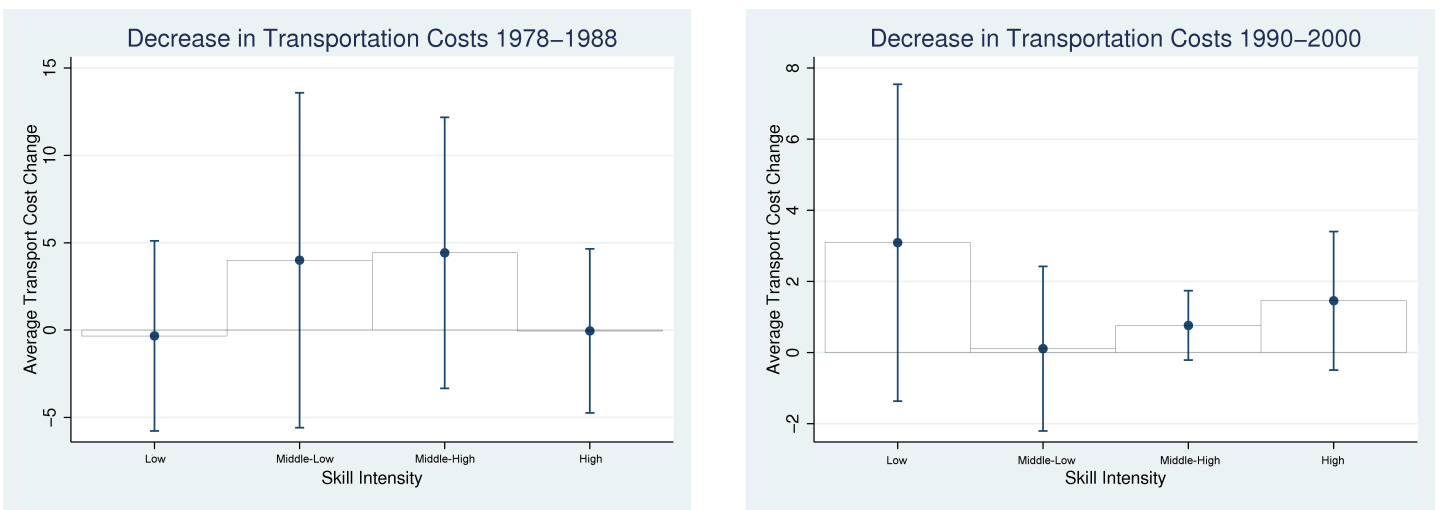

Figure 5: Changes in U.S. Transportation Costs (Insurance and Freight). One Std. Dev. bars are shown. Source: Feenstra database. 


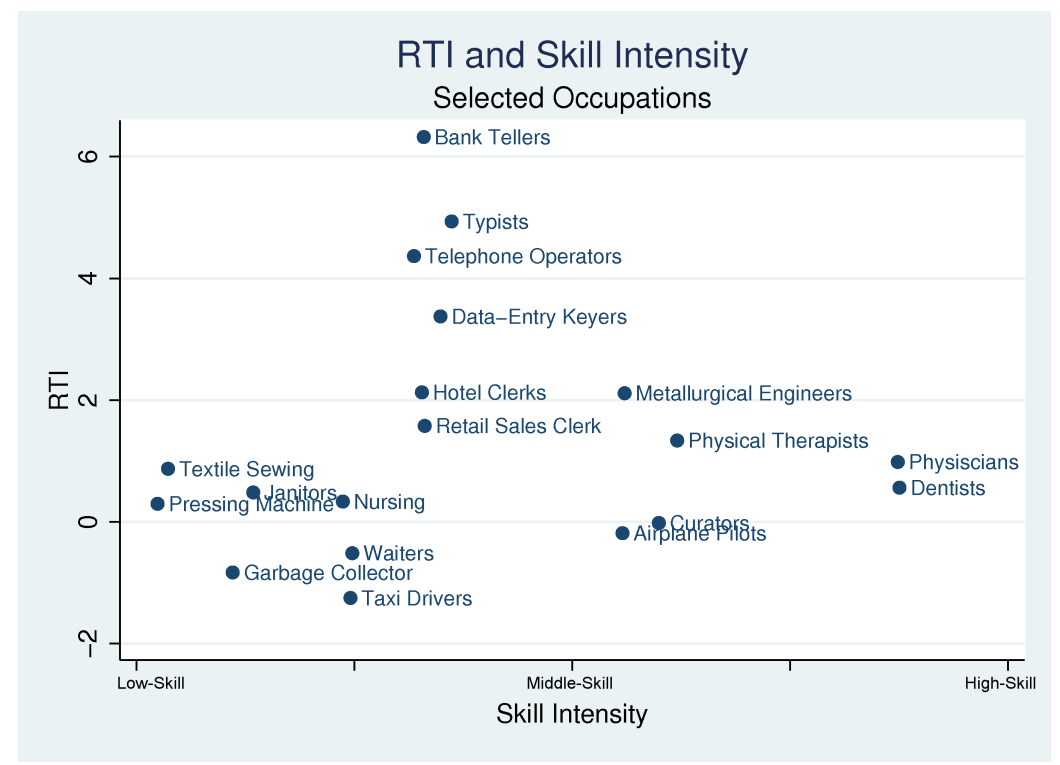

Figure 6: Examples of RTI for Selected Occupations. Source: Autor and Dorn (2009).

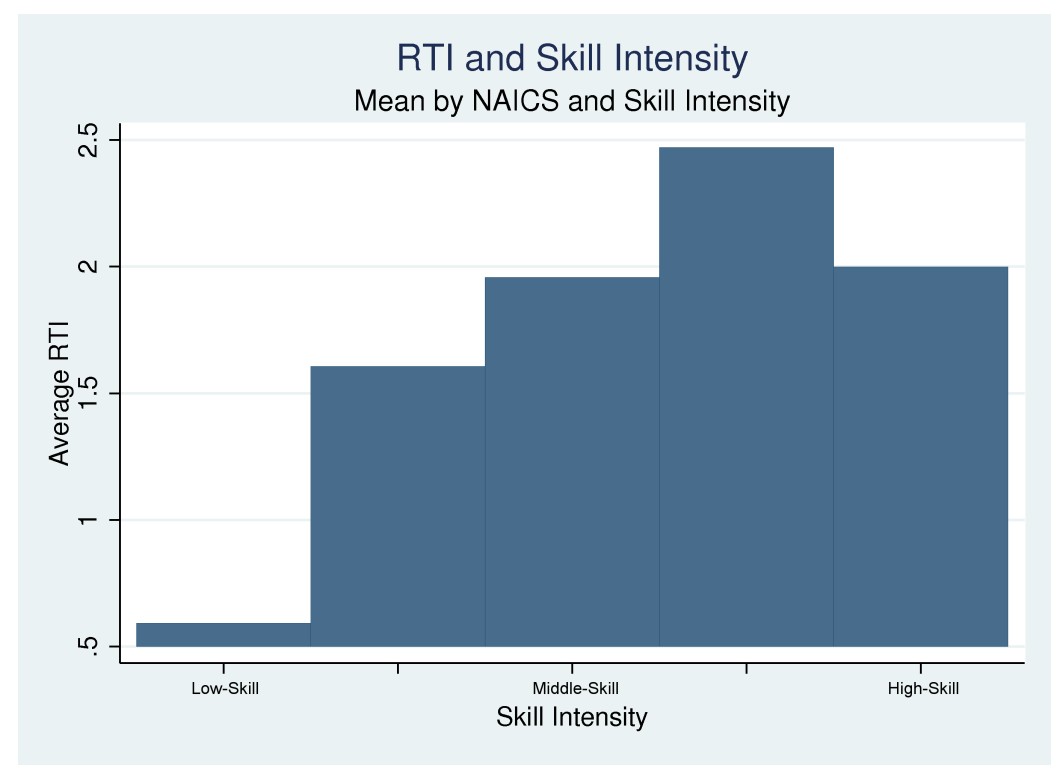

Figure 7: Average Skill Intensity by U.S. Industry. Source: Autor and Dorn (2009). 


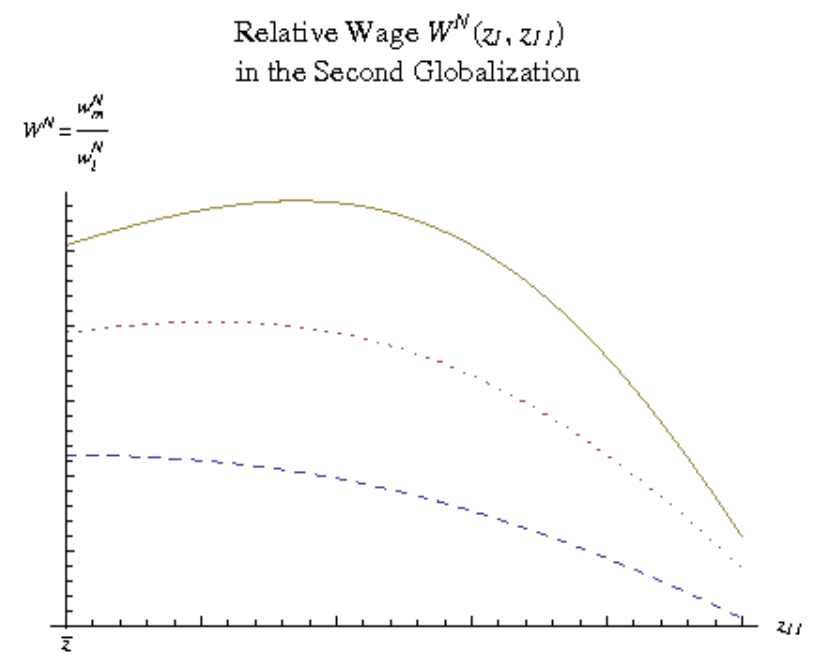

Figure 8: Interdependence in the North. This plot assumes $\bar{z}=1 / 2$. The dashed line is for $z_{I}=0$, dotted for $z_{I}=.2$ and regular line for $z_{I}=.3$.

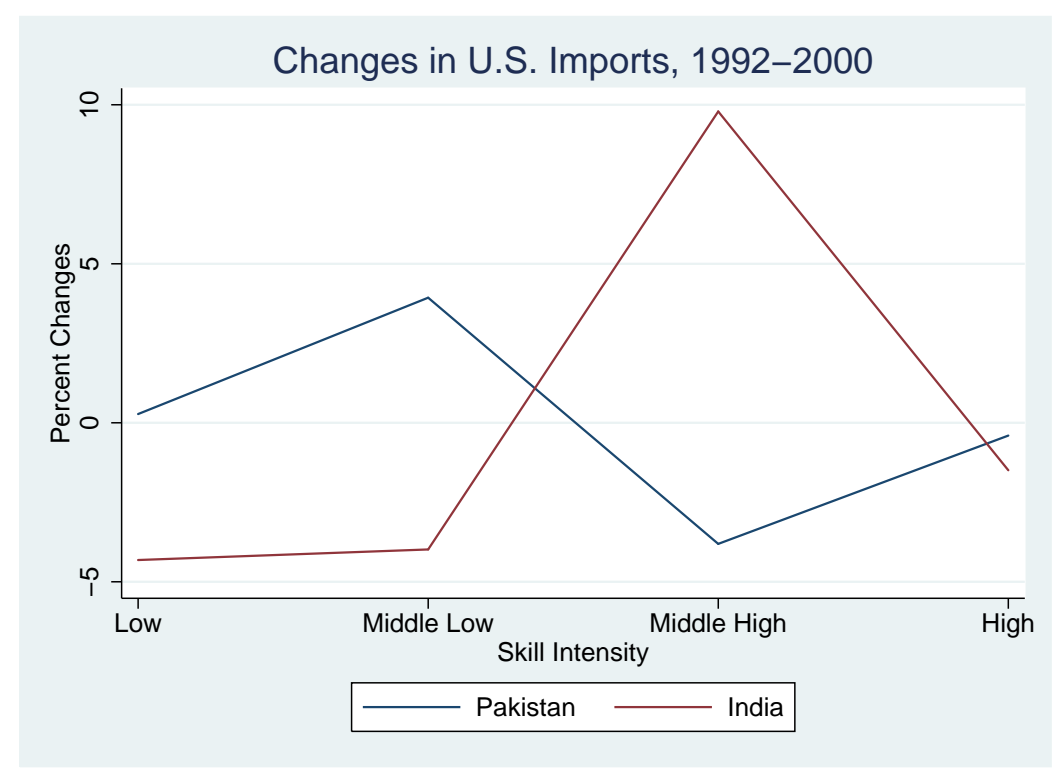

Figure 9: Changes in U.S. imports from India and Pakistan for different skill levels. Source: Feenstra U.S. Imports Database. 